\title{
Consumption-based Equity Valuation
}

\author{
Bach, Christian; Christensen, Peter O.
}

Document Version

Accepted author manuscript

Published in:

Review of Accounting Studies

DOI:

10.1007/s11142-016-9358-y

Publication date:

2016

License

Unspecified

Citation for published version (APA):

Bach, C., \& Christensen, P. O. (2016). Consumption-based Equity Valuation. Review of Accounting Studies, 21(4), 1149-1202. https://doi.org/10.1007/s11142-016-9358-y

Link to publication in CBS Research Portal

\section{General rights}

Copyright and moral rights for the publications made accessible in the public portal are retained by the authors and/or other copyright owners and it is a condition of accessing publications that users recognise and abide by the legal requirements associated with these rights.

Take down policy

If you believe that this document breaches copyright please contact us (research.lib@cbs.dk) providing details, and we will remove access to the work immediately and investigate your claim. 


\section{Consumption-based Equity Valuation}

\section{Christian Bach and Peter Ove Christensen}

Journal article (Post print version)

CITE: Consumption-based Equity Valuation. / Bach, Christian; Christensen, Peter 0.

In: Review of Accounting Studies, Vol. 21, No. 4, 2016, p. 1149-1202.

The final publication is available at Springer via http://dx.doi.org/10.1007/s11142-016-9358-y

Uploaded to Research@CBS: June २०17 


\title{
Consumption-based equity valuation*
}

\author{
Christian Bach \\ Danske Commodities \\ Denmark \\ Peter O. Christensen ${ }^{\dagger}$ \\ Department of Finance \\ Copenhagen Business School, Denmark
}

April 4, 2016

Forthcoming in Review of Accounting Studies

${ }^{*}$ We thank seminar participants at Aarhus University, London Business School, the Eighth Accounting Research Workshop in Basel 2013, and especially Jim Ohlson (editor) and two anonymous referees for helpful comments. In addition, we are grateful for detailed comments and suggestions from Bent Jesper Christensen, Mateusz P. Dziubinski, Hans Frimor, Bjørn N. Jørgensen, Claus Munk, Stephen H. Penman, and Scott Richardson. We gratefully acknowledge research support from CREATES (funded by the Danish National Research Foundation), D-CAF, Columbia University, and the Danish Social Science Research Council.

${ }^{\dagger}$ Corresponding author: Peter O. Christensen, Department of Finance, Copenhagen Business School, Solbjerg Plads 3, DK-2000 Frederiksberg, Denmark; email: poc.fi@cbs.dk. 


\begin{abstract}
Using a CCAPM-based risk-adjustment model, we perform yearly valuations of a large sample of stocks listed on NYSE, AMEX, and NASDAQ over a 30-year period. The model differs from standard valuation models in the sense that it adjusts forecasted residual income for risk in the numerator rather than through a risk-adjusted cost of equity in the denominator. The risk adjustments are derived based on assumptions about the time-series properties of residual income returns and aggregate consumption rather than on historical stock returns. We compare the performance of the model with several implementations of standard valuation models, both in terms of median absolute valuation errors (MAVE) and in terms of excess returns on simple investment strategies based on the differences between model and market prices.

The CCAPM-based valuation model yields a significantly lower MAVE than the best performing standard valuation model. Both types of models can identify investment strategies with subsequent excess returns. The CCAPM-based valuation model yields time-series of realized hedge returns with more and higher positive returns and fewer and less negative returns compared with the time-series of realized hedge returns based on the best performing standard valuation model for holding periods from one to five years. In a statistical test of one-year-ahead excess return predictability based on the models' implied pricing errors, the CCAPM-based valuation model is selected as the better model.

Using the standard series of aggregate consumption and the nominal price index, a reasonable level of relative risk aversion, and calibrated growth rates in the continuing value at each valuation date, the CCAPM-based valuation model produces small risk adjustments to forecasted residual income and low continuing values. Compared with standard valuation models, it relies less on estimated parameters and speculative elements when aggregating residual earnings forecasts into a valuation.
\end{abstract}

JEL Classifications: C22, C32, C51, C53, G11, G12, G14, G32.

Keywords: Equity valuation, residual income, risk-adjusted discounting, CAPM, CCAPM. 


\section{Introduction}

Making comprehensive valuations of equities remains a challenge both in practice and in theory. We do have models like the CAPM or Fama-French models to determine a risk-adjusted cost of capital used to discount expected future residual income, but these models are typically quite imprecise when applied. The valuations obtained are very sensitive to estimates of betas and market (factor) risk premiums. This sensitivity is due to the estimated risk premium being compounded through the discount factor leading to exponentially increasing risk adjustments to expected future residual income. This pattern of risk adjustments is justified if all shocks to residual income are fully persistent on a percentage basis, i.e., if residual income follows a geometric Brownian motion. However, if residual income contains both persistent and transitory shocks implying processes with mean reversion, then exponentially increasing risk adjustments through a constant risk premium in the risk-adjusted cost of capital are likely to be grossly overstated. There is overwhelming evidence of mean reversion in residual income for most firms and industries (e.g., Nissim and Penman 2001). This is the strong force of competition, real options to expand and abandon, and entry and exit in product markets at work.

In this article, we perform yearly valuations of a large sample of companies listed on NYSE, AMEX, and NASDAQ over a 30-year period using a Consumption-based Capital Asset Pricing Model (CCAPM) for risk adjustment. The model separates discounting for time in the denominator (through a readily observable term structure of risk-free interest rates) from discounting for risk in the numerator. This separation allows us to model the time-series properties of firms' residual income as mean-reverting processes. We assume residual income follows a first-order autoregressive process, while aggregate consumption and inflation follow geometric Brownian motions with constant expected growth rates. This allows us to derive closed-form expressions for the model-implied risk adjustment to forecasted residual income in the numerator.

We compare the performance of the CCAPM-based valuation model with the performance of a large variety of implementations of the standard CAPM and three-factor Fama-French based valuation models, with the latter type of models adjusting for risk through a riskadjusted cost of equity in the denominator. Model performance is measured along two dimensions: (a) the efficient market perspective - is the model able to fit the cross-section of stock prices as well as the level of stock prices across business cycles? - and (b) the fundamental valuation perspective - is the model able to identify "cheap" and "expensive" stocks?

Along the first dimension, model values are compared with the market prices of stocks. 
Using calibrated growth rates in the continuing value at each valuation date common to all firms in the sample, the best performing implementation of the standard valuation model produces a median absolute valuation error (MAVE) of 36\%, while the CCAPM-based valuation model yields a MAVE of $23 \%$.

Along the second dimension, a simple buy-and-hold investment strategy analysis is performed. At each valuation date and for each valuation model, the stocks are placed in equally weighted buy, hold, and sell portfolios based on whether the model suggests that the stocks are cheap or expensive. The performance of the portfolios is measured by a large set of alternative performance measures based on subsequent (i.e., out-of-sample) returns. ${ }^{1}$ Both types of models can identify investment strategies with subsequent excess returns. ${ }^{2}$ The CCAPM-based valuation model yields time-series of realized hedge returns with more and higher positive returns and fewer and less negative returns compared with the time-series of realized hedge returns based on the best performing standard valuation model, i.e., higher average realized returns (4.5\% versus 3.0\%) and higher average Sortino ratios (78\% versus $34 \%$ ) for holding periods from one to five years. In a statistical test of one-year-ahead excess return predictability based on the models' implied pricing errors, the CCAPM-based valuation model is selected as the better model with a $p$-value of 0.0077 .

Our implementations of the residual income valuation models are based on analysts' consensus forecasts of earnings up to five years ahead from the I/B/E/S database and an assumption of constant payout ratios to generate implied forecasts of residual income. The key difference between the implementations of the CCAPM-based and the standard valuation models is how these residual income forecasts are aggregated into a valuation.

Using standard estimation procedures, the median estimated risk premium (i.e., beta times the geometric equity premium relative to short-term Treasuries) is $6-7 \%$ for the standard valuation models, and the median calibrated growth rate in the continuing value (at year five) to match the level of stock prices at each valuation date is close to $5 \%$. In other words, both the estimated risk premiums and the continuing values play important roles in aggregating analysts' forecasts into a valuation using standard valuation models.

Betas and equity premiums are hard to estimate reliably even if the CAPM or the FamaFrench model is the true model. As Penman (2007, page 691) states it:

"Compound the error in beta and the error in the risk premium and you have a considerable problem. The CAPM, even if true, is quite imprecise when applied.

\footnotetext{
${ }^{1}$ These performance measures include excess returns relative to the value-weighted market index, abnormal returns (i.e., with one-factor CAPM and three-factor Fama-French risk adjustments), benchmark returns based on firm characteristics, Sharpe, and Sortino ratios as well as the time-series of realized hedge returns (long in buy portfolios and short in sell portfolios).

${ }^{2}$ See Frankel and Lee 1998 for a first study along these lines using the standard valuation model.
} 
No one knows what the market premium is. And adopting multifactor pricing models adds more risk premiums and betas to estimate. These models contain a strong element of smoke and mirrors."

Due to estimation errors, Levi and Welch (2014) show (using historical data and simulation studies with known parameters) that users of the CAPM or the Fama-French model should shrink the beta estimates (even on the industry level) almost to the point where there is no cross-sectional variation in the cost of equity. Moreover, they report that, since 1970, the geometric (arithmetic) equity premium relative to long-term Treasuries has been only $0.8 \%$ (1.7\%) annually. ${ }^{3}$ In their study, standard applications of both the CAPM and the FamaFrench model failed to predict rates of returns given estimated inputs, often even with the wrong sign (see also Frazzini and Pedersen 2014). They argue it is much more important to account for the easy-to-estimate term-premium on long- versus short-term Treasuries than hard-to-estimate risk premiums in risk-adjusted expected rates of returns.

Using the standard series of aggregate consumption, the nominal price index from the NIPA tables and a reasonable level of relative risk aversion (equal to two), the CCAPMbased valuation model produces small estimated risk adjustments to forecasted residual income (with a median NPV in the order of $2 \%$ of current book value). It is well known that the stochastic variation in the aggregate consumption series is not sufficient to produce an equity premium relative to short-term Treasuries around $6 \%$ for reasonable levels of relative risk aversion (e.g., Mehra and Prescott 1985 and the extensive literature that followed on the equity premium and risk-free rate puzzles). It is possible that too much averaging, smoothing and estimation go into the constructing of this series, but it is worth noticing that risk adjustments may be lower than suggested by this literature, once the term-premium is properly accounted for by discounting risk-adjusted expected residual income with easy-toestimate zero-coupon interest rates. In any case, using the CCAPM-based valuation model, the impact of difficult-to-estimate risk adjustments play a much smaller role in aggregating residual earnings forecasts into a valuation than when standard valuation models are used.

While one- and two-year-ahead analyst forecasts are, in general, quite reasonable and in accordance with subsequent accounting earnings, the reported growth rates for three- to fiveyear-ahead forecasts seem to be substantially upwardly biased (e.g., Frankel and Lee 1998 and Hermann et al. 2008). In a robustness check in the online appendix, we demonstrate that excluding these long-term growth forecasts of analysts in our forecasting of future residual income leads to significantly lower valuation accuracy, especially for the standard valuation model. Hence, even though these long-term forecasts might be substantially upwardly biased,

\footnotetext{
${ }^{3}$ The standard procedure of using a 10-year Treasury rate plus a risk premium relative to a short-term Treasury rate may thus be double-counting for the term-premium leading to an overstated cost of equity.
} 
they still seem to provide useful information for valuing stocks in the cross-section.

If the risk adjustments are upwardly biased (in the standard valuation models) or downward biased (in the CCAPM-based valuation model) and the analysts' growth forecasts are upwardly biased, we can make a counterbalancing error in the growth rate in the continuing values. We do this by calibrating the growth rates in the continuing values at each valuation date to match the level of stock prices at that date (i.e., such that the median valuation error is equal to zero). Of course, this requires that there be no systematic differences in the biases in the cross-section of firms for each valuation model.

Using the standard valuation model, the medians of the calibrated growth rates in the continuing value over the sample period are substantial, i.e., 5\% (8\%) when including (excluding) the analysts' long-term forecasts in the analysis. Growth rates of expected future value creation in the continuing value of that economically unreasonable magnitude suggest that the standard valuation model must make a "counterbalancing error" of risk-adjusting too much through the risk-adjusted cost of equity in the denominator.

Using the CCAPM-based valuation model, the medians of the calibrated growth rates in the continuing value over the sample period are much lower, i.e., $-10 \%$ (1\%) when including (excluding) the analysts' long-term forecasts in the analysis. Hence, the continuing value plays a much smaller role in valuations with the CCAPM-based valuation model. In this model, risk-adjusted expected value creation is implied to "fade" to zero in the long-run (at least when including analysts' growth forecasts from three to five years ahead), consistent with the economic theory of competition, real options to expand and abandon, and entry and exit in product markets. ${ }^{4}$ On the other hand, the fading of risk-adjusted expected value creation may also be a result of counterbalancing the upward bias in the analysts' longterm growth forecasts and downward biased risk adjustments due to the smooth aggregate consumption series. Our analysis cannot separate these potential effects.

We implement several versions of the standard valuation model using an estimated cost of equity as the discount rate for discounting expected future residual income and for calculating residual income as comprehensive income minus the cost of equity times the opening book value of equity for the period. The implementations differ with respect to (a) growth assumptions for residual income after using five-year-ahead analysts' forecasts, (b) whether we use a one-factor CAPM or a three-factor Fama-French model for estimating the cost of equity, and (c) the historical period over which we estimate the factor risk premiums at each valuation date. In general, we find that the valuation accuracy (measured primarily as median absolute valuation errors) is better for long estimation periods of factor risk

\footnotetext{
${ }^{4}$ Note that this does not imply the accounting is unbiased - it only means that the expected unrecorded goodwill has a limit equal to the risk adjustment for unrecorded goodwill.
} 
premiums (30 years or more). The valuation accuracy is substantially better for the onefactor CAPM than for the three-factor Fama-French model, and this result is consistent with comparable results of Nekrasov and Shroff (2009). Hence, the additional risk factors in the Fama-French model do not seem to offset the additional estimation noise and the lack of stability in estimating more risk premiums even for long estimation periods (at least for valuation purposes).

There is a large empirical literature comparing the valuation accuracy of mathematically equivalent (given clean or super-clean surplus accounting) versions of the standard valuation model such as discounted cash flow models and accounting-based models such as the residual income model and the abnormal earnings growth model. ${ }^{5}$ The differences between these equivalent models are a matter of how value is represented in the valuation equation. ${ }^{6}$ The empirically documented differences in valuation accuracy (usually favoring the residual income model) of these versions of the standard valuation model are primarily due to the length of the forecast horizon and how the continuing value is modeled after the forecast horizon (e.g., Lundholm and O'Keefe 2001; Penman 2001; Jorgensen et al. 2011).

Our empirical comparison of the valuation accuracy and the investment performance of the standard valuation models versus the CCAPM-based valuation model is different in nature. We cast both types of models in the residual income valuation framework, but the two model types differ fundamentally in how they adjust for risk in future residual income. The standard valuation model is based on a single-period CAPM equilibrium framework, which can only be meaningfully extended to a multi-period setting if the cost of capital is constant and shocks to residual income are fully persistent on a percentage basis, i.e., residual income follows a geometric Brownian motion (which precludes residual income from being negative in any future period). ${ }^{7}$ The CCAPM-based valuation model has its roots in

\footnotetext{
${ }^{5}$ In the discounted cash flow model, the value of equity is equal to the NPV of future cash flows to the equity holders. In the residual income model, the value of equity is equal to the current book value of equity plus the NPV of future residual income. In the abnormal earnings growth model, the value of equity is the capitalized value of the sum of forward earnings and the one-year-ahead NPV of future abnormal earnings growth. All three types of models also come in versions on a net operating asset basis assuming that the financial activities are recorded on a mark-to-market basis in the reformulated financial statements (e.g., Ohlson 1995; Feltham and Ohlson 1995; Feltham and Ohlson 1996; Feltham and Ohlson 1999; Christensen and Feltham 2003; Ohlson and Juettner-Nauroth 2005; Christensen and Feltham 2009; Penman 2007).

${ }^{6}$ The discounted cash flow model is nothing but a version of the accounting-based models assuming cash flow accounting. However, as has been the practice for several hundred years, financial statements have been on an accrual basis to recognize value creation on a more timely basis than cash flow accounting does. The appealing feature of accounting-based valuation models is that they recognize value creation on a more timely basis (through accruals) with their principle of counterbalancing errors: any errors you may make in current accounting book values or earnings are precisely offset in the NPV of future residual income or abnormal earnings growth.

${ }^{7}$ See Section 5.4 in Christensen and Feltham (2009), and Brennan (2003) for the necessary and sufficient constant relative risk condition for a constant return risk premium.
} 
classical multi-period asset pricing theory (cf., Rubinstein 1976), and it allows for stochastic interest rates, stochastic inflation, and time-varying risk adjustments to expected future residual income depending on the time-series properties (such as mean reversion) of future residual income.

Our study is closely related to that of Nekrasov and Shroff (2009). They perform an empirical comparison of the valuation accuracy of standard valuation models and models with fundamentals-based risk adjustments. While their valuation accuracy results for the standard models are very similar to ours, their fundamentals-based risk adjustment model is different. Their starting point is the same, namely that no-arbitrage and clean surplus accounting imply that equity value can be written as the current book value of equity plus the discounted value (with risk-free interest rates) of expected future residual income minus a risk adjustment determined by the covariance between residual income and a valuation index (see Feltham and Ohlson 1999). That is, they also discount for risk in the numerator and discount for time with risk-free interest rates in the denominator. However, no-arbitrage and clean surplus accounting alone do not inform about how the valuation index and, thus, the risk adjustment is determined. The valuation index is a mathematical construct with no economic content.

While no-arbitrage pricing is useful for pricing redundant assets, more structure is needed to price primitive securities like equities. Nekrasov and Shroff (2009) follow the path in the linear factor-based asset pricing literature (like the Fama-French model) making the ad hoc assumption that the valuation index can be written as a linear function of some (accountingbased) pricing factors like the Fama-French factors. Further assuming that the covariance between residual income returns and the valuation index is constant across time (which amounts to assuming no persistence in residual income returns) allows them to estimate fundamentals- or accounting-based risk adjustments to expected future residual income. ${ }^{8}$

While there is no economic theory supporting the form of fundamentals-based risk adjustments by Nekrasov and Shroff (2009), they obtain substantial improvements in valuation accuracy compared to both the standard one-factor CAPM and three-factor Fama-French models using a risk-adjusted cost of equity. The improvements are of the same magnitude as the improvements we obtain using the CCAPM-based valuation model. ${ }^{9}$ This suggests that making the risk adjustments in the numerator rather than through a risk-adjusted cost

\footnotetext{
${ }^{8}$ Christensen and Feltham (2009) show in their Section 5.3 that mark-to-market accounting leads to residual income returns with zero persistence. For other accounting policies, there is likely to be some persistence in residual income returns if there is persistence in the underlying cash flows.

${ }^{9}$ Nekrasov and Shroff (2009) do not evaluate the different types of models from a fundamental valuation perspective. Rather, they find that their fundamentals-based risk measures can assist in understanding some of the standard "anomalies" such as the value premium.
} 
of equity in the denominator is the key to improving valuation accuracy, and maybe not so much whether the risk adjustments are based on an ad hoc factor model or they are based on an equilibrium approach using, for example, the CCAPM. However, it is generally preferred to have a well-founded economic theory behind empirical endeavors.

Our study and that of Nekrasov and Shroff (2009) compare alternative comprehensive valuation models determining equity values in terms of current book value and net present value of future residual income. The key difference is how the net present values of uncertain future residual income are calculated. Another branch of the equity valuation literature compares comprehensive valuation models to multiple-based equity valuation models in terms of valuation accuracy (e.g., Liu, Nissim, and Thomas 2002). The latter models examine which financial attributes (such as analysts' one- and two-year-ahead earnings forecasts) best explain market prices of comparable firms in a linear regression. The multiples are determined at each valuation date so as to minimize the distance between market prices and model values (i.e., the product of estimated multiples and financial attributes) in a given industry of comparable firms. The key difference between the two types of models is that the latter uses contemporaneous market prices of comparable firms to minimize the distance between market prices and model values in the industry (such as the MAVE), whereas the former does not use market prices of comparable firms but estimated discount rates, risk adjustments, and growth rates in the continuing value.

Not surprisingly (given the research design), the multiple-based equity valuation models perform better than comprehensive valuation models in terms of valuation accuracy. The key result from the multiple-based equity valuation models is that simple models using only analysts' two-year-ahead earnings forecasts (and perhaps forecasted short-term earnings growth) perform well. For example, using the sample period 1982-1999 and 81 industries to estimate year- and industry-specific multiples, Liu, Nissim, and Thomas (2002) find a MAVE of $16 \%$ using only the forecasted two-year-ahead price-earnings ratio.

Eliminating estimation noise and simplicity seem to be virtues in matching market prices of equities. Multiple-based equity valuation models do not inform about the determinants of fitted multiples and, thus, do not allow comparisons of equities across industries and time. Hence, while multiple-based equity valuation models are useful to get a reading of what the market price would be on a non-traded stock, these models are less useful as a tool to challenge market prices of traded stocks based on fundamental analysis - unless it is assumed all firms in the industry must have the same multiples, regardless of earnings persistence, risk, growth, etc.; see Penman and Reggiani (2013).

The remainder of the article is organized as follows. Section 2 presents the standard and CCAPM-based valuation models. Section 3 describes the data sources and the sam- 
pling method. Section 4 describes the methods of implementing the valuation models. The empirical results are presented in Section 5, and Section 6 concludes.

In the online appendix, we perform a few robustness checks concerning (a) the impact of including financial companies and utilities in the empirical analysis and (b) the impact of excluding the analysts' long-term growth forecasts from the analysis. The key results are (a) the relative empirical performance of the two model types is basically unchanged by including financial companies and utilities, but the calibrated median growth rates in continuing values are reduced (as should be expected based on the accounting principles used by these types of firms), and (b) the valuation accuracy deteriorates by excluding the analysts' long-term growth forecasts and the median calibrated growth rates increase significantly for both model types, but the empirical investment performance is almost as good as when these long-term growth forecasts are included in the analysis.

\section{Valuation models}

In this section we present the standard and the CCAPM accounting-based valuation models, and we show how they are based on classical asset pricing theory. The accounting structure is similar in both types of models - they anchor the valuation in current book value and then add a premium equal to the discounted forecasted residual income. The models differ in their adjustment for risk. In the standard model, discounting for risk is done in the denominator through a CAPM-based (or multi-factor) risk-adjusted discount factor. In the CCAPMbased valuation model, forecasted residual income is adjusted for risk in the numerator, and the risk-adjusted forecasted residual income is then discounted by the risk-free discount factor. Hence, the latter disentangles the discounting for risk from the discounting for the timing of forecasted residual income.

\subsection{Fundamentals of asset pricing}

Assuming no arbitrage and mild regularity conditions, a strictly positive state-price deflator (SPD) $m$ exists such that the price at date $t, V_{t}$, of any asset in the economy is given by

$$
V_{t}=\sum_{\tau=1}^{\infty} \mathrm{E}_{t}\left[m_{t, t+\tau} d_{t+\tau}\right]
$$

where $d$ is the dividend from the asset, and $\mathrm{E}_{t}[\cdot]$ is the conditional expectations operator given information at date $t$. The SPD discounts both for risk and timing of dividends. As shown by Feltham and Ohlson (1999), an equivalent representation of the price separates 
the adjustment for time from the adjustment for risk as

$$
V_{t}=\sum_{\tau=1}^{\infty} B_{t, t+\tau}\left\{\mathrm{E}_{t}\left[d_{t+\tau}\right]+\operatorname{Cov}_{t}\left(d_{t+\tau}, Q_{t, t+\tau}\right)\right\},
$$

where $B_{t, t+\tau}=\left(1+\iota_{t, t+\tau}\right)^{-\tau}=\mathrm{E}_{t}\left[m_{t, t+\tau}\right]$ is the date $t$ price of a zero-coupon bond paying one dollar at date $t+\tau, \iota_{t, t+\tau}$ is the date $t$ zero-coupon interest rate for maturity $t+\tau$, and $Q_{t, t+\tau}=\frac{m_{t, t+\tau}}{B_{t, t+\tau}}$ is a valuation index.

An important criticism of the above dividend discount model (DDM) for valuation is that, while a dividend payment in effect gives the investor a dollar amount, it is not necessarily an indication of value creation by the firm (in the short term). A firm can borrow in order to pay dividends, and Miller and Modigliani (1961) show that such a financing decision does not create value: dividends are important to equity values but the dividend policy is not. The residual income valuation (RIV) model reflects value creation in a more timely and transparent form and is therefore often preferred in equity valuation. As shown by Feltham and Ohlson (1999), the RIV model yields the same valuation as the DDM if the accounting system satisfies the clean surplus relation (CSR):

$$
b v_{t+\tau}=b v_{t+\tau-1}+n i_{\tau}-d_{\tau}
$$

where $b v$ is book value of equity, $n i$ is net income, and $d$ is the dividend (i.e., net transactions with shareholders). That is, besides payments to shareholders, all changes in book value of equity must be recorded in (comprehensive) net income. Defining residual income as $r i_{t+\tau}=n i_{t+\tau}-\iota_{t+\tau-1, t+\tau} b v_{t+\tau-1}$, Feltham and Ohlson (1999) show that no-arbitrage and CSR imply that the DDM in (1) can be rewritten as the RIV model, i.e.,

$$
V_{t}=b v_{t}+\sum_{\tau=1}^{\infty} B_{t, t+\tau}\left\{\mathrm{E}_{t}\left[r i_{t+\tau}\right]+\operatorname{Cov}_{t}\left(r i_{t+\tau}, Q_{t, t+\tau}\right)\right\}
$$

The various asset pricing models handle the risk adjustments, i.e., the conditional covariances between future residual income and the valuation index, in different ways. In order to address this, further assumptions are needed for identifying the valuation index.

\subsection{Standard CAPM-based valuation model}

The CAPM is a single-period theory, and it can be derived in several ways. One way is to assume that the payoffs on the asset and the market portfolio are jointly normally distributed, and that the valuation index can be written as a function of the payoff on the 
market portfolio. Stein's Lemma can then be applied to rewrite the single-period equivalent of (1) as

$$
V_{t}=B_{t, t+1}\left\{\mathrm{E}_{t}\left[d_{t+1}+V_{t+1}\right]+\mathrm{E}_{t}\left[Q_{t, t+1}^{\prime}\left(d_{t+1}^{M}+V_{t+1}^{M}\right)\right] \operatorname{Cov}_{t}\left(d_{t+1}^{M}+V_{t+1}^{M}, d_{t+1}+V_{t+1}\right)\right\}
$$

where $d^{M}+V^{M}$ is the payoff on the market portfolio. Since this formula prices any asset with normally distributed dividends and therefore also the market portfolio, it is straightforward to show (by substituting out $\mathrm{E}_{t}\left[Q_{t, t+1}^{\prime}\left(d_{t+1}^{M}+V_{t+1}^{M}\right)\right]$ from the formula for the market portfolio) that the expected return of any asset is given by

$$
\mathrm{E}_{t}\left[R_{t+1}\right]=\iota_{t, t+1}+\left(\mathrm{E}_{t}\left[R_{t+1}^{M}\right]-\iota_{t, t+1}\right) \frac{\operatorname{Cov}_{t}\left(R_{t+1}^{M}, R_{t+1}\right)}{\operatorname{Var}_{t}\left(R_{t+1}^{M}\right)}=\iota_{t, t+1}+r p_{t, t+1},
$$

where $R$ is the return $\left(=\left(d_{t+1}+V_{t+1}-V_{t}\right) / V_{t}\right)$ on the asset, $R^{M}$ is the return on the market portfolio, and $r p$ is the return risk premium, which is determined as the product of the asset's beta, i.e., $\frac{\operatorname{Cov}\left(R^{M}, R\right)}{\operatorname{Var}\left(R^{M}\right)}$, and the market risk premium, i.e., $\mathrm{E}\left[R^{M}\right]-\iota$. If an asset has low (high) returns in periods in which the market returns are low, then the asset has a higher (lower) required expected return than the riskless return, implying a lower (higher) asset value than the expected payoff discounted at the risk-free rate. In the CAPM, the return on the market portfolio is the only priced risk factor.

In our empirical study, we also consider the Fama-French multi-factor model. It can be derived in a similar manner as the CAPM from an assumption that the valuation index can be written as a linear function of priced risk factors. The return risk premium $r p$ can in this case be written as weighted sum of the factor risk premiums with the asset's factor betas as weights.

To calculate the expected return via (5), one has to estimate the asset beta and the expected excess return on the market portfolio (see Section 4.1 below). To find the value of the asset using the CAPM method, the risk-free rate, the beta, and the expected excess return on the market portfolio must be assumed to be constants (see the discussion in Christensen and Feltham 2009, Chapter 2). These are similar assumptions to those in the CAPM valuation model implementations of Nekrasov and Shroff (2009) and Jorgensen et al. (2011). With these assumptions, the standard valuation model can equivalently be formulated as

$$
V_{t}=\sum_{\tau=1}^{\infty} \frac{\mathrm{E}_{t}\left[d_{t+\tau}\right]}{(1+\iota+r p)^{\tau}}
$$

This is the standard dividend discount model (DDM) stating that the value of an asset is determined as its expected future dividends discounted by its risk-adjusted cost of capital. 
Defining residual income as $r i_{t+\tau}^{S T D}=n i_{t+\tau}-(\iota+r p) b v_{t+\tau-1}$ and using the clean surplus relation (2), it is straightforward to rewrite (6) as the standard RIV model as

$$
V_{t}=b v_{t}+\sum_{\tau=1}^{\infty} \frac{\mathrm{E}_{t}\left[r i_{t+\tau}^{S T D}\right]}{(1+\iota+r p)^{\tau}}
$$

That is, the value of common shareholders' equity is the sum of the book value of equity and future expected residual income discounted by the risk-adjusted cost of equity. Dividing through by the book value of equity at the valuation date allows us to write the marketto-book ratio as the normal market-to-book ratio plus a book value premium equal to the risk-adjusted discounted value of expected future Residual Income Returns, $R I R_{t, t+\tau}^{S T D} \equiv$ $r i_{t+\tau}^{S T D} / b v_{t}$, i.e.,

$$
\frac{V_{t}}{b v_{t}}=1+\sum_{\tau=1}^{\infty} \frac{\mathrm{E}_{t}\left[R I R_{t, t+\tau}^{S T D}\right]}{(1+\iota+r p)^{\tau}} .
$$

The practical considerations involved in calculating the value of common shareholders' equity in a large-sample empirical study using (7) will be discussed and explained in Section 4.1.

\subsection{CCAPM-based valuation model}

As for the standard valuation model in (7), we base the CCAPM valuation model on the clean surplus relation (2) and use residual income (RI). However, instead of discounting expected future RI for both risk and time through a risk-adjusted discount rate in the denominator (and a risk-adjusted capital charge in the definition of residual income), we first make assumptions about the time-series properties of residual income returns and aggregate consumption to obtain a closed-form expression for the risk adjustment in (3) directly. Hence, forecasted future RIs are adjusted for risk in the numerator, and the risk-adjusted forecasted future RIs are then discounted by zero-coupon interest rates.

The RIV model (3) prices all assets, but further assumptions are needed for the model to be empirically implementable, since no-arbitrage and CSR only ensure the existence of the valuation index but not what determines this index. One can proceed from (3) in various ways. One possibility is to make an ad hoc assumption that the valuation index is an affine function of some pricing factors and then use a standard factor-based model approach like the Fama-French approach. This is the approach followed by Nekrasov and Shroff (2009), and they use 10 years of historical accounting data to calculate a constant risk-adjustment term using accounting-based Fama-French factors. Naturally, this places strong assumptions on the data, such as many consecutive years of accounting data, and the fact that a constant risk adjustment implicitly assumes no persistence and growth in residual 
income (see below). Furthermore, there is no economic foundation of the model. We follow the equilibrium approach by Christensen and Feltham (2009) and place assumptions on the time-series properties of the variables in the model and from these time-series properties, we obtain an explicit solution of the time-varying risk adjustment terms in (3).

We assume that a Pareto efficient equilibrium exists (as in the CAPM), that investors have time-additive power utility, i.e., $u(x)=\frac{1}{1-\gamma} x^{1-\gamma}$, where $\gamma$ is the common relative risk aversion parameter and $x$ is real consumption, and that real aggregate consumption and the nominal price index are log-normally distributed. Let $c i$ denote the consumption index, which is a measure of real aggregate consumption and the nominal price level in the economy. ${ }^{10}$ Under the additional assumption of future residual income and the consumption index being jointly normally distributed, Christensen and Feltham (2009) show that (3) can be reformulated as

$$
\frac{V_{t}}{b v_{t}}=1+\sum_{\tau=1}^{\infty} B_{t, t+\tau}\left[\mathrm{E}_{t}\left(R I R_{t, t+\tau}\right)-\operatorname{Cov}_{t}\left(R I R_{t, t+\tau}, c i_{t+\tau}\right)\right]
$$

where $R I R_{t, t+\tau} \equiv \frac{r i_{t+\tau}}{b v_{t}}, r i_{t+\tau}=n i_{t+\tau}-\iota_{t+\tau-1, t+\tau} b v_{t+\tau-1}, c i_{t+\tau}=c i_{t+\tau}^{R}+\ln \left(p_{t+\tau}\right)=$ $\gamma \ln \left(c_{t+\tau}\right)+\ln \left(p_{t+\tau}\right)$ and $c$ is aggregate consumption per capita, whereas $p$ is a nominal price index. The consumption index can be estimated from observed data and an assumption about $\gamma$ as will be discussed in Section 4.2.

Following Christensen and Feltham (2009), we assume a simple first-order autoregressive model for $R I R$ given by ${ }^{11}$

$$
R I R_{t, t+\tau}-R I R_{t}^{o}=\omega_{r}\left[R I R_{t, t+\tau-1}-R I R_{t}^{o}\right]+\varepsilon_{t+\tau}
$$

where $R I R_{t}^{o}$ is the structural level of the residual income return at the valuation date $t,\left|\omega_{r}\right|<$ 1 is the first-order autoregressive parameter determining the speed of convergence to the structural level of residual income return, and $\varepsilon$ are i.i.d. normally distributed innovations. The motivation behind assuming an autoregressive process with mean reversion towards a structural level is inspired by, for example, Penman (2007), who argues that, in practice, the strong force of competition (and entry and exit) is often assumed to drive residual income towards a structural level, such as an industry average.

\footnotetext{
${ }^{10}$ With our assumption of standard power utility, the consumption index is the product of relative risk aversion and log aggregate consumption per capita plus the log of the price index (see Christensen and Feltham 2009).

${ }^{11}$ For simplicity, we consider a simplified version (compared to Christensen and Feltham 2009) of the process for residual income returns in which there is no growth in the structural level of residual income returns. Allowing for growth does not yield substantially improved empirical results.
} 
We assume that the consumption index $c i$ follows the simple process

$$
c i_{t+\tau}-c i_{t+\tau-1}=v+\delta_{t+\tau},
$$

which is consistent with the standard asset pricing assumption of aggregate consumption being log-normally distributed (i.e., aggregate consumption per capital follows a geometric Brownian motion). The assumption of a constant growth rate $v$ further implies constant interest rates (see Christensen and Feltham 2009, Chapter 5). The innovations in the above equations, $\varepsilon$ and $\delta$, are assumed to be serially uncorrelated and to be distributed as

$$
\left[\begin{array}{c}
\varepsilon_{t+\tau} \\
\delta_{t+\tau}
\end{array}\right] \sim N\left(\mathbf{0},\left\{\begin{array}{cc}
\sigma_{r}^{2} & \sigma_{r a} \\
\sigma_{r a} & \sigma_{a}^{2}
\end{array}\right\}\right) .
$$

That is, $\varepsilon$ and $\delta$ are contemporaneously correlated, which reflects the systematic risk in residual income returns.

Solving equations (9) and (10) recursively yields

$$
\begin{aligned}
R I R_{t, t+\tau} & =R I R_{t}^{o}+\omega_{r}^{\tau}\left(R I R_{t, t}-R I R_{t}^{o}\right)+\sum_{s=0}^{\tau-1} \omega_{r}^{s} \varepsilon_{t+\tau-s} \\
c i_{t+\tau} & =c i_{t}+\tau v+\sum_{s=0}^{\tau-1} \delta_{t+\tau-s} .
\end{aligned}
$$

From the residual income return equation (11), it follows that

$$
\begin{aligned}
\mathrm{E}_{t}\left[R I R_{t, t+\tau}\right] & =R I R_{t}^{o}+\omega_{r}^{\tau}\left(R I R_{t, t}-R I R_{t}^{o}\right), \\
\operatorname{Var}_{t}\left[R I R_{t, t+\tau}\right] & =\sigma_{r}^{2} \frac{1-\omega_{r}^{2 \tau}}{1-\omega_{r}^{2}} .
\end{aligned}
$$

From the consumption index equation (12), it similarly follows that

$$
\mathrm{E}_{t}\left[c i_{t+\tau}\right]=c i_{t}+\tau v, \quad \operatorname{Var}_{t}\left[c i_{t+\tau}\right]=\tau \sigma_{a}^{2}
$$

Furthermore, the covariance between the two series is given by

$$
\operatorname{Cov}_{t}\left(R I R_{t, t+\tau}, c i_{t+\tau}\right)=\sigma_{r a} \frac{1-\omega_{r}^{\tau}}{1-\omega_{r}} .
$$

The risk adjustment to the expected residual income return is determined by the covariance between the residual income return $R I R$ and the consumption index ci. The higher the 
covariance, the larger is the adjustment for risk, since the asset provides a less valuable hedge against periods with low consumption. The risk adjustment depends on the contemporaneous covariance between the innovations in residual income returns and the consumption index $\sigma_{r a}$ and on the persistence of deviations of residual income returns from their structural level $\omega_{r}$. For $\sigma_{r a}>0$, the risk adjustment is increasing in the persistence parameter $\omega_{r}$. That is, the slower is the reversion of residual income returns to the long-run structural level, the higher is the risk adjustment. This is an intuitive result, since future residual income returns are more uncertain, the lower is the degree of mean reversion. The covariance between $R I R$ and $c i$ (i.e., the risk adjustment) is converging towards an upper limit of $\sigma_{r a} /\left(1-\omega_{r}\right)$. In the simple case of instant mean reversion (i.e., zero persistence), i.e., $\omega_{r}=0$, the risk adjustment to the expected residual income returns is constant (as in the Nekrasov and Shroff 2009 model), i.e., $\operatorname{Cov}_{t}\left(R I R_{t, t+\tau}, c i_{t+\tau}\right)=\sigma_{r a}$.

A major criticism of the standard model is that it discounts expected future residual income by a constant risk-adjusted cost of equity. Ang and Liu (2004) emphasize that this is not a reasonable assumption, and using a calibrated version of their model, they show that economically significant valuation errors can be induced. Christensen and Feltham (2009) show that the implicit risk adjustments to expected residual income returns from using a constant return risk premium grows exponentially over time, and that this growth is amplified by growth in the expected residual income returns. This is consistent with the fundamental RIV model (3) when residual income returns follow a geometric Brownian motion with zero mean reversion. On the other hand, the CCAPM valuation model has time-varying adjustments for risk determined by the persistence of deviations of residual income returns from their structural level, for example, due the sustainability of competitive advantages.

Further assumptions are needed for the model to be empirically implementable in a large-sample empirical study. These will be described in Section 4.2.

\section{Data and sample}

Having set the theoretical framework for the two types of valuation models, this section describes the data needed for the empirical valuation study using the standard CAPMbased valuation model (in Section 2.2) and the CCAPM-based valuation model (in Section $2.3)$.

We perform valuations at the end of April each year from 1982 until 2008. We use analysts' one- and two-year consensus forecasts from the month of April available through the I/B/E/S database. Applying analysts' forecasts of the long-term growth (LTG) rate to 
the two-year forecast, we calculate three- to five-year-ahead earnings forecasts. The I/B/E/S database contains April earnings per share (EPS) forecasts for 16,918 US companies (see Table 1). By applying forecasts from the month of April, all companies with financial years following the calendar year are expected to have made their annual financial report public at the time of the forecast. This mitigates information asymmetry between investors at the valuation dates. Furthermore, analysts often update their earnings forecasts after the release of an annual report in order to reflect their updated information. Thus, April earnings forecasts are expected to be relatively more updated than earnings forecasts in other months of the year. The financial year of most companies follows the calendar year, and we only keep these companies in the sample. Table 1 shows the impact of sampling on the number of distinct tickers/companies available in the analysis.

\section{Insert Table 1 about here}

In order to ensure a sufficient quality of the consensus EPS forecasts, we exclude median forecasts based on less than three analysts. This approach is not standard in the literature, and it reduces the number of distinct companies in the sample to 9,658 (see Table 1), which is a relatively large reduction in the sample size. However, requiring at least three April analysts' forecasts for both one- and two-year-ahead forecasts and long-term growth-rate forecasts mitigates the size effect on returns of small versus large firms documented in prior literature (ensuring that we only retain relatively large firms with a high degree of analyst following in the sample).

In addition to the $\mathrm{I} / \mathrm{B} / \mathrm{E} / \mathrm{S}$ database, we use accounting information from the Compustat database and stock price information from the CRSP database. The three databases use different unique tickers for the companies, and none of these provide the link to the tickers used in the other databases. A link between these databases is constructed based on the cibeslink macro to link I/B/E/S to Compustat and the iclink macro to link I/B/E/S to CRSP. ${ }^{12,13}$ Since the links between databases are imperfect and there are differences in the variety of companies in the different databases, the sample size is reduced to 8,262 companies (see Table 1). Most companies in the data set are traded on the major stock exchanges (AMEX, NYSE, and NASDAQ). We exclude companies not traded on these exchanges.

As will be shown later, the standard CAPM-based valuation model is highly dependent

\footnotetext{
${ }^{12}$ These macros are available through WRDS. To link the databases to each other, we use the IDUSM data set from I/B/E/S and the STOCKNAMES data set from CRSP.

${ }^{13}$ The linking quality between I/B/E/S and CRSP is based on a score from 0 to 6 , where 0 is the best match. We do not accept scores above 1 , which should ensure that we only keep correctly matched firms. A small fraction of the I/B/E/S tickers have multiple links to CRSP tickers. In these cases, we only keep the company if it has a linking score of 0 and the score is unique.
} 
on the estimates of LTG. Therefore, we need both one- and two-year-ahead earnings forecasts as well as the LTG rate at the time of the valuation. If one of these forecasts is unavailable at a valuation date, we exclude that observation from the sample. As is seen from Table 1, this reduces the sample dramatically to 3,377 companies, yielding 20,499 distinct firm-year observations.

As in Fama and French (2001), we exclude utilities (SIC codes 4900-4949) and financial firms (SIC codes 6000-6999), limiting the analysis to 14,220 firm valuation dates and 2,526 distinct firm tickers spanning the period from 1982 to 2008.

The end-of-year book value of common equity (CSE) (Compustat item \#60), net income before extraordinary items (net income/IBCOM) (Compustat item \#237), dividends paid to common equity (Compustat item \#21), and total assets (Compustat item \#6) are from Compustat. The stock price (CRSP variable PRC) and shares outstanding (CRSP variable SHROUT) are from CRSP. Betas for each company in each valuation year are estimated using monthly excess stock returns (CRSP) and monthly excess returns on the three FamaFrench factors (from the Fama-French database). The method is briefly described in Section 4.1. Following Nekrasov and Shroff (2009), we use a 60 month sample for each estimation whenever such data is available from CRSP. If 60 months of data is not available, we allow for a minimum of 36 months. The betas are estimated using 60 observations for most estimations (10,752); 1,384 estimations are based on less than 60 but at least 36 observations, while 2,084 estimations were excluded from the valuation due to lack of data. Following the same approach, betas are also calculated using the Fama-French three-factor approach. After the estimations of betas, the sample size is limited to 12,136 valuations on 1,938 distinct companies.

For the estimation of betas, we use the one-month Treasury rate as the risk-free rate. In the standard CAPM-based valuation model we use, as is standard in both practice and in the literature, a 10-year Treasury rate for calculating the risk-adjusted cost of equity used for discounting and calculating expected future residual income. In the CCAPM-based valuation model, we use zero-coupon interest rates from the FED database for discounting risk-adjusted expected future residual income and the corresponding one-year-ahead forward rates for calculating expected future residual income. In order to examine the impact of using the yield curve in the CCAPM-based valuation model, we also implement this model with a constant risk-free rate equal to the 10 -year Treasury rate.

A number of observations are deleted during the valuation process using the CCAPMbased valuation model, as will be described in Section 4.2. Thus, the results reported in the results section are calculated using 10,024 valuations on 1,827 distinct companies. This is fewer valuations compared to valuation articles such as those of Nekrasov and Shroff 
(2009) and Jorgensen et al. (2011). There are several reasons for this. (a) we include only nonfinancial and non-utility in the sample; (b) we require each valuation to have both a one-year and two-year-ahead forecast as well as a forecast of LTG; (c) we do not include consensus forecasts based on less than three analysts' forecast; (d) unlike Jorgensen et al. (2011), we require 36 observations in the estimation of betas; (e) additional sampling must be done to apply two distinct valuation models and not just the standard valuation model as used by Jorgensen et al. (2011). The Points (a)-(c) each reduce the sample significantly, as seen from Table 1, while point (d) also has some impact. As a robustness check, we also perform the analysis relaxing the criterion in point (a), and we show that the inclusion of utilities and financial firms has no impact on the basic conclusions from the analysis. Further robustness checks show that the CCAPM-based valuation model fares well both with and without the LTG rate of analysts (see the online appendix).

In order to implement the CCAPM-based valuation model, we need data on real consumption per capita as well as on the price index. The consumption data is the usual series used in the CCAPM asset pricing literature. It is obtained from the NIPA tables available from Bureau of Economic Analysis. The price index is also available from the NIPA tables. Details on calculation of the consumption index will be given in Section 4.2.

\section{Valuation procedure}

This section describes how the valuation models are implemented in our large-sample empirical study. Both models require a number of assumptions to be made in the empirical implementation, and the empirical results depend on these assumptions. As a consequence, we will perform the valuation based on several different assumptions, for example, about the growth rate in the continuing value and about the factor risk-premium estimation. While the standard model places stronger requirements on data availability, the implementation issues are well explained in the literature and, therefore, we only briefly explain how we implement this model. We will be more detailed in describing how we implement the CCAPM model.

\subsection{Standard model procedure}

The standard valuation model cast in the residual income framework is equation (7):

$$
\frac{V_{t}}{b v_{t}}=1+\sum_{\tau=1}^{\infty} \frac{\mathrm{E}_{t}\left[R I R_{t, t+\tau}^{S T D}\right]}{(1+\iota+r p)^{\tau}}
$$


While the valuation equation may appear very simple, it is debated in the literature how best to implement it. The model requires forecasting of future residual income and estimation of the risk-adjusted discount factor taking account of discounting for both time and risk. The model, as stated in (14), includes an infinite sum. Since forecasting into the infinite future is not feasible, a truncation point is usually chosen, and a continuing value is calculated using simplifying assumptions to account for the remaining. We discuss these elements in turn.

\subsubsection{Discounting for time and risk}

In the valuation equation (14), discounting for time and risk is done using a risk-adjusted discount rate reflecting the risk associated with the payoffs to the equityholders, i.e., by the cost of equity determined as the risk-free interest rate plus a return risk premium, $\iota+r p$. As is standard in most valuation studies, we chose the risk-free rate to be the 10-year Treasury yield (to reflect an average interest rate over the yield curve), and we allow for several priced risk factors. Hence, the cost of equity is expressed as

$$
\iota+r p=\iota_{10 y}+\beta \cdot R P
$$

where $\iota_{10 y}$ is the 10 -year Treasury yield, $\beta$ is a vector of factor sensitivities, and $R P$ is a vector of factor risk premiums. We estimate the betas at each valuation date for each firm using up to 60 observations of monthly data in the regression:

$$
R-\iota_{1 m}=a+\beta_{M K T} \operatorname{Ex} R^{M}+\beta_{S M B} R^{S M B}+\beta_{H M L} R^{H M L}+\varepsilon,
$$

where $\iota_{1 m}$ is the one-month Treasury yield, $R$ is the return on the asset of interest, $\operatorname{Ex} R^{M}$ is the excess return on the market portfolio, $R^{S M B}$ is the return on the Fama-French small minus big portfolio, and $R^{H M L}$ is the return on the Fama-French high minus low portfolio. We run this regression both including only the market factor (i.e., the standard CAPM assuming $\beta_{S M B}=\beta_{H M L}=0$ ) and including all three Fama-French factors.

The estimated betas are used to calculate the cost of equity as (when using all three factors):

$$
\iota+r p=\iota_{10 y}+\beta_{M K T} R P^{M}+\beta_{S M B} R P^{S M B}+\beta_{H M L} R P^{H M L},
$$

where $R P^{M}, R P^{S M B}$, and $R P^{H M L}$ are the historical risk premiums on the market, small minus big, and high minus low portfolios, respectively. ${ }^{14}$ We estimate $R P^{M}, R P^{S M B}$, and $R P^{H M L}$ as the geometric average of (excess) returns over the rolling windows of 5, 10, 20, and 30 years preceding the estimation date as well as the full period from 1926 until the

\footnotetext{
${ }^{14}$ The cost of equity is estimated using monthly data and is then annualized.
} 
month preceding the estimation date. Hence, we obtain 10 different measures for the cost of equity for each firm at each valuation date (i.e., standard CAPM versus Fama-French models and five different rolling windows for the estimation of the factor risk premiums in both models). In very rare cases, the cost of equity is below $2 \%$, and we winsorize it to $2 \%$. This winsorization has effect more often in the three-factor than in the one-factor case, and more so using few observations in the estimation of risk premiums than when many observations are used.

\subsubsection{Forecasting book value of equity and residual income}

The standard valuation model in (14) requires forecasts of residual income $r i_{t+\tau}^{C A P M}=n i_{t+\tau}-$ $(\iota+r p) b v_{t+\tau-1}$, which means that we must make forecasts of future net income and book values of equity. In order to obtain these forecasts, we use the most recent book value of equity, which is calculated from accounting data from the Compustat database for the previous year. Following Nissim and Penman (2001), we calculate common shareholders' equity as

Common shareholder equity $(\mathrm{CSE})=$ Common equity $(\# 60)$

+ Preferred treasury stock (\#227) - Preferred dividends in areas (\#242).

To forecast residual income, we use analysts' estimates of five-year-ahead forecasts of net income $n i$ from the $\mathrm{I} / \mathrm{B} / \mathrm{E} / \mathrm{S}$. Residual income for the first forecast year can then be calculated directly from the residual income formula $r i_{t+1}=n i_{t+1}-(\iota+r p) b v_{t}$. Since the book value of equity is unknown at future dates, we follow the standard procedure in the literature (e.g., Frankel and Lee 1998; Claus and Thomas 2001; Gebhardt et al. 2001; Easton 2002) and forecast this value through the CSR (2) by assuming a constant payout ratio equal to the current payout ratio, which is calculated as

$$
\frac{\text { Dividends Common/Ordinary }(\# 21)}{\text { Income Before Extraordinary Items (\#237) }} \text {. }
$$

If the firm has negative net income (\#237), we calculate the payout ratio by dividing current dividends with $6 \%$ of total assets $(\# 6)$, i.e., the historical payout ratio. If the current payout ratio is above $100 \%$, we first calculate it by dividing current dividends with $6 \%$ of total assets. If this also yields a payout ratio larger than $100 \%$, we winsorize at $100 \%$ to ensure that the company does not liquidate itself.

Having a starting value for book value of equity, forecasts of net income, and a constant payout ratio, one can forecast future book values of equity through the CSR (2). With the 
forecasted book value of equity, forecasted net income, and a constant cost of equity, we forecast residual income five years ahead.

\subsubsection{Continuing value}

The final element in the valuation equation (14) is the infinite sum. We truncate 12 years ahead and let residual income evolve according to a Gordon growth formula thereafter. We follow Jorgensen et al. (2011) and implement several assumptions for the continuing values in the standard valuation model to accommodate suggestions made in the literature as how to calculate continuing values. The general formula we apply is given by

$$
\frac{V_{t}}{b v_{t}}=1+\sum_{\tau=1}^{5} \frac{\mathrm{E}_{t}\left[R I R_{t, t+\tau}^{S T D}\right]}{(1+\iota+r p)^{\tau}}+\sum_{\tau=6}^{12} \frac{\mathrm{E}_{t}\left[R I R_{t, t+\tau}^{S T D}\right]}{(1+\iota+r p)^{\tau}}+\frac{\mathrm{E}_{t}\left[R I R_{t, t+12}^{S T D}\right](1+g)}{(1+\iota+r p)^{12}\left(\iota_{10 y}+r p-g\right)}
$$

where $g$ is the constant growth rate in residual income after year 12 . The third part of the above formula forecasts and discounts residual income from 6 to 12 years ahead. We assume an intermediate convergence period from 6 to 12 years ahead, where we let residual income converge to a certain level as described below. Twelve years ahead, we calculate a continuing value based on residual income in year 12 and constant growth in residual income thereafter.

The first approach is a no growth case (CAPMC), in which we assume residual income remains constant after the explicit forecast period if $\mathrm{E}_{t}\left[\mathrm{ri}_{t+5}^{S T D}\right]>0$ and assume $g=0$ in the continuing value. If $\mathrm{E}_{t}\left[r i_{t+5}^{S T D}\right]<0$, we let residual income revert towards zero in the intermediate period and assume $g=0$ in the continuing value. The second approach assumes residual income grows $3 \%$ in both the intermediate period and the continuing term (CAPMG) if $\mathrm{E}_{t}\left[\mathrm{ri}_{t+5}^{S T D}\right]>0$, and otherwise we let it revert to zero. The third approach assumes the return on equity $\mathrm{E}_{t}\left[\frac{n i}{b v}\right]$ reverts to the historical industry average in the intermediate period and that residual income remains constant after 12 years (CAPMI). The industry definitions follow the Fama and French (1997) 48-industry classification. In the CAPMI approach, we forecast residual income based on a growth rate calculated such that the return on equity equals the historical average industry return on equity at year $t+12$. If the return on equity is nonpositive at the valuation date, a feasible growth rate cannot be calculated for the firm

of interest and, thus, we let the return on equity revert linearly to the historical industry return on equity. 


\subsection{CCAPM model procedure}

There are several approaches to implementing the CCAPM valuation model in equation (8):

$$
\frac{V_{t}}{b v_{t}}=1+\sum_{\tau=1}^{\infty} B_{t, t+\tau}\left(\mathrm{E}_{t}\left(R I R_{t, t+\tau}\right)-\operatorname{Cov}_{t}\left(R I R_{t, t+\tau}, c i_{t+\tau}\right)\right)
$$

Christensen and Feltham (2009) discuss using the information contained in the term structure of interest rates to derive the implied preference dependent parameters of the model, such as the relative risk aversion parameter $\gamma$, which is contained in the consumption index. While this is a valid and appealing approach, we have chosen to implement the simpler approach of assuming a particular relative risk aversion parameter $\gamma=2$, which is a commonly used value for $\gamma$ in the asset pricing literature (e.g., Campbell and Cochrane 1999; Wachter 2006). Fortunately, untabulated results show that the sensitivity of our empirical results is low with respect to this parameter (within what is normally considered to be reasonable bounds from one to ten). This is in stark contrast to the well-documented high sensitivity of valuations in standard valuation models with respect to the market risk premium (or factor risk premiums). No one knows the market risk premium and the investors' relative risk aversion, and both quantities are likely to vary over the business cycle (see Cochrane 2005a). It is an empirical question which approach works best, but we leave it for future research.

Having specified the relative risk aversion parameter, we can use historical aggregate consumption and price level data to estimate the time-series properties of the consumption index, and we can use historical accounting data to estimate the time-series properties of residual income returns. Our implementation of the CCAPM valuation model follows an eight step procedure outlined below. (See the appendix for an application of this procedure for valuing a specific company, Alcoa Inc., at a specific valuation date, April 15, 2002.)

(a) We use zero-coupon interest rates from the FED database to calculate the risk-free discount factors $B_{t, t+\tau}$, and we use the implied forward rates as estimates of future spot interest rates in the calculation of future residual income returns. ${ }^{15}$ In order to examine the impact of using a non-flat yield curve, we also consider a variation of the model in which the 10-year Treasury yield is used as a constant risk-free discount rate and as the risk-free spot rate in the calculation of future residual income returns.

\footnotetext{
${ }^{15}$ This is consistent with our process for the consumption index, which as noted implies deterministic interest rates. For more general consumption index processes with, for example, mean reversion, interest rates become stochastic and, therefore, there is an additional risk-adjustment term in the accounting-based residual income model using forward rates in the calculation of residual income (see Christensen and Feltham 2009, Chapter 3).
} 
(b) Net income and book value of equity are forecasted one to five years ahead using analysts' forecasts and an assumption of a constant payout ratio as in the standard model. Using the interest rate assumptions from step (a) allows us to construct forecasts of future residual income returns. An alternative would be to use the estimated time-series model of residual income returns (from step (d) below) to forecast future returns, but we have chosen to use analysts forecasts, because these forecasts are based on a much richer information set than just past residual income returns.

(c) As in the standard model, we use an intermediate period of forecasts from year six to year 12. For simplicity, we assume that residual income returns remain constant in the intermediate period if $\mathrm{E}_{t}\left[R I R_{t, t+5}\right]>0$ and increase to zero if $\mathrm{E}_{t}\left[R I R_{t, t+5}\right]<0$.

(d) The risk adjustments in (13) require an estimate of the persistence of residual income returns in the time-series model of these returns in (9) and an estimate of the contemporaneous covariance between the innovations in (9) and (10). We assume that the sustainability of competitive advantages and the accounting principles used are similar for all firms within an industry and, thus, we estimate the structural level of residual income returns $R I R_{t}^{o}$ and the persistence of residual income returns $\omega_{r}$ at the industry level (for which we again use the Fama and French 1997 48-industry classification). At each valuation date, we estimate the first-order autoregressive equation (omitting cross-section subscripts) ${ }^{16}$

$$
R I R_{t, t+\tau}=R I R_{t}^{o}+\omega_{r}\left(R I R_{t, t+\tau-1}-R I R_{t}^{o}\right)+\varepsilon_{t+\tau}, \quad \tau=-7,-6, \ldots, 0,
$$

where the LHS is a time series of $R I R$ from seven years before the valuation date (using the book value of equity at the valuation date for each firm in the calculation of firmspecific historical residual income returns). The industry-specific parameters $R I R_{t}^{o}$ and $\omega_{r}$ are estimated using a simple panel data model for each industry at each valuation date. $^{17}$ We take the average of the firms' estimated error terms at each date in the panel data estimation as the estimate of the industry-specific innovation at that date. This provides a time-series of estimated industry-specific innovations, which, in step (f) below, can be used to estimate the industry-specific contemporaneous covariance between residual income returns and the consumption index.

\footnotetext{
${ }^{16}$ Consistent with the definition of residual income in the CCAPM valuation model, we use historical one-year Treasury yields in the calculation of historical residual income returns.

${ }^{17}$ Convergence of the estimation could not be reached in a few cases, and in few cases the estimated persistence was larger than one, i.e., $\left|\omega_{r}\right| \geq 1$. These cases are deleted from the sample.
} 
(e) The consumption index is calculated from historical data from the NIPA tables as

$$
c i_{t+\tau}=\gamma \ln \left(c_{t+\tau}\right)+\ln \left(p_{t+\tau}\right)
$$

where $c=\left(\frac{c^{N}}{p^{N}}+\frac{c^{S}}{p^{S}}\right) / I$, with $N$ and $S$ denoting nondurable and services, respectively, and $I$ is the population size. The weighted price index is calculated as $p=\frac{c^{N}}{c^{N}+c^{S}} p^{N}+$ $\frac{c^{S}}{c^{S}+c^{N}} p^{S}$. Consistent with the asset pricing literature, we assume as noted above that the constant relative risk aversion is equal to 2 , i.e., $\gamma=2$. We assume constant growth in the consumption index, and we use seven years of data to estimate the consumption index equation (10):

$$
c i_{t+\tau}-c i_{t+\tau-1}=v+\delta_{t+\tau}, \quad \tau=-7,-6, \ldots, 0 .
$$

This yields a time series of estimated innovations $\delta$ in the consumption index at each valuation date.

(f) With the results from steps (d) and (e), we estimate the contemporaneous covariance between residual income returns and the consumption index, $\sigma_{r a}$, as the simple historical covariance between the time series of estimated innovations $\varepsilon$ and $\delta$. The industry-specific risk adjustments to expected future residual income returns at each valuation date are then calculated using the equation for the risk adjustment (13):

$$
\operatorname{Cov}_{t}\left(R I R_{t, t+\tau}, c i_{t+\tau}\right)=\sigma_{r a} \frac{1-\omega_{r}^{\tau}}{1-\omega_{r}}
$$

We use this risk adjustment to forecasted residual income returns for years until the truncation year $t+12$. The parameters of the risk adjustment are constant and must be known at the valuation date. The persistence $\omega_{r}$ is estimated in step (d) as an industryand valuation-year specific parameter. While $\sigma_{r a}$ is constant for each valuation date, the covariances in (19) determining the risk adjustments to future expected residual income returns will be time varying.

(g) As for the standard valuation model, we truncate the model at year $t+12$ and use a Gordon growth formula for the continuing value. We assume the risk-adjusted expected future residual income returns grow at a constant rate $\mu$ after year $t+12$, and we use the longest zero-coupon interest rate in the FED database for discounting all risk-adjusted expected future residual income returns after year $t+12$, denoted $\iota_{t, \infty}$. The continuing value is discounted by the 12-year zero-coupon interest rate. In the empirical study, we use several assumptions for the growth parameter $\mu$ to provide fair comparisons to 
the best implementation of the standard valuation model (see Section 5.1).

(h) Finally, the value of the common shareholders equity is calculated by adding the elements of the previous steps in the valuation equation (18):

$$
\begin{aligned}
\frac{V_{t}}{b v_{t}}=1 & +\sum_{\tau=1}^{5} \frac{\mathrm{E}_{t}\left(R I R_{t, t+\tau}\right)-\sigma_{r a} \frac{1-\omega_{r}^{\tau}}{1-\omega_{r}}}{\left(1+\iota_{t, t+\tau}\right)^{\tau}}+\sum_{\tau=6}^{12} \frac{\mathrm{E}_{t}\left(R I R_{t, t+\tau}\right)-\sigma_{r a} \frac{1-\omega_{r}^{\tau}}{1-\omega_{r}}}{\left(1+\iota_{t, t+\tau}\right)^{\tau}} \\
& +\frac{\left[\mathrm{E}_{t}\left(R I R_{t, t+12}\right)-\sigma_{r a} \frac{1-\omega_{r}^{12}}{1-\omega_{r}}\right](1+\mu)}{\left(1+\iota_{t, t+12}\right)^{12}\left(\iota_{t, \infty}-\mu\right)},
\end{aligned}
$$

where the third term on the RHS depends on whether $\mathrm{E}_{t}\left(R I R_{t, t+5}\right)$ is positive or negative (see step (c)). If an equity value is estimated to be negative, it is deleted from the sample.

\section{Empirical results}

To evaluate the empirical performance of the CCAPM- and the standard CAPM-based valuation models, we compare the two model types along two dimensions. First, we compare the models' ability to match the cross-section of stock prices as well as the level of stock prices across business cycles. This is the market efficiency perspective, which assumes that the market prices of stocks are always right. Any comprehensive valuation model makes assumptions about, for example, growth, risk, and how risk is priced, and is thus merely a model of reality. If a particular valuation model provides a relatively good match to market prices, the model may also provide better guidance compared to other models when there is no observable market price, for example, when determining the offering price of privately held companies for their initial public offerings, when determining equity values in management buyouts and takeovers, and even in the evaluation of strategies and capital budgeting decisions within firms. We follow the literature (such as Nekrasov and Shroff 2009) and examine the performance of the two model types along this dimension in Section 5.1 using the median absolute valuation error (MAVE) as our primary performance measure.

We then examine the ability of the two model types to identify cheap and expensive stocks. This is the fundamental valuation perspective (e.g., Penman 2007), which assumes that market prices of stocks may deviate from their fundamental values temporarily, but that market prices will eventually revert to their fundamental values as determined by the valuation model. If a valuation model can identify cheap and expensive stocks, then this

must be reflected in excess returns on trading strategies buying cheap stocks and selling expensive stocks. We examine the performance of the two model types along this dimension 
in Section 5.2 using excess returns on simple buy-and-hold strategies as our primary performance measure. We use both short- and longer-term holding periods (one to five years) to account for the fact that it may take time and market pricing errors might even get larger before mispriced stocks eventually revert to their fundamental values.

\subsection{Comparing model values with market prices}

Table 2 reports descriptive statistics of key variables used as input to the valuation models. The data set is split into three nine-year sub-periods, and both mean and median measures are reported. Both the mean and median price per share are decreasing through the sampling period, and this pattern is opposite to what is observed by Nekrasov and Shroff (2009). One explanation of this difference is that Nekrasov and Shroff (2009) require each company to have 10 consecutive yearly observations of accounting data, and this can introduce a strong survivorship bias in their dataset. This explanation is supported by the dividend payouts, which are showing the same decreasing pattern as documented by Nekrasov and Shroff (2009) but are smaller, compared to their reported values. All other variables show largely the same patterns and values shown by Nekrasov and Shroff (2009). The book value per share and the book-to-market ratio have decreased since the 1980s, reflecting the bull market over most of the two later sub-periods. The mean (median) dividend payout has been decreasing steadily through the period from a high of $32.4 \%(31.9 \%)$ in the earliest sub-period to $14.9 \%(0 \%)$ in the latest sub-period. Since these payout ratios only include dividends in the classical sense and not other types of distributions to shareholders, it is likely that much of this decrease can be explained by the documented increase in share repurchases. ${ }^{18}$

The mean return on equity is increasing through the sample period, while the median is largely unchanged. ${ }^{19,20}$ This pattern is matched relatively well by analysts' forecasts of return on equity for the subsequent one and two years. The long-term growth rate is increasing slightly for both the mean and the median values through the sampling period. Analysts, in general, seem to be biased towards reporting too high growth rates. Average growth rates well in excess of 10 percent predicted for all sub-periods cannot be realized in reality over substantial periods. While analysts' expectations about the short term are reasonably accurate (or moderately upwardly biased), forecasts of long-term growth are strongly upwardly

\footnotetext{
${ }^{18}$ A relative increase in share repurchases is documented by Dittmar (2000) for the period 1977-1996 and by Fama and French (2001) for the period 1978-1999.

${ }^{19}$ Beginning-of-year book value is not available for all companies since it requires accounting data from a year before the valuation date. Therefore, ROE is reported using end-of-year book value.

${ }^{20}$ It has been shown (see Ciccone 2002) that earnings management is more likely to take place in companies with negative earnings, which might influence the reported ROE numbers. However, due to the properties of accrual accounting, this must result in lower ROE in subsequent periods. Therefore, seen over a large number of companies and years, mean and median ROE could still be unbiased.
} 
biased as also noted by, for example, Frankel and Lee (1998) and Hermann et al. (2008).

The well known decline in Treasury yields is also seen in Table 2. For the first subperiod, the average 10-year risk-free rate was $9.2 \%$, while it has decreased to $4.5 \%$ in the last sub-period. A similar pattern is seen for the CAPM-based cost of equity, which decreases from a mean (median) of $16 \%(15.7 \%)$ in the first sub-period to $11.5 \%(10.4 \%)$ in the last sub-period. Largely similar declines are seen from the first to the second sub-period for the cost of equity based on the three-factor Fama-French model. However, the second and the third sub-periods have almost the same mean and median cost of equity.

Insert Table 2 about here

Table 3 reports the mean and median absolute valuation errors of the standard CAPMbased model for different assumptions about the calculation of the market risk premium and different assumptions about the growth rate in the continuing value. ${ }^{21}$ Table 4 shows similar results when the three-factor Fama-French model is used in calculating the risk-adjusted cost of equity. The percentage valuation errors (VE) are calculated as $(P-V) / P$, and the absolute percentage valuation errors (AVE) are calculated as $|P-V| / P$, where $P$ is the market price and $V$ is the model value. It is clear from the two tables that the standard onefactor CAPM-based valuation model yields, in general, lower valuation errors both in terms of VE and AVE than the three-factor Fama-French-based valuation model. Hence, while the additional factors might have explanatory power for cross-sectional differences in shortterm stock returns (within sample), these factors have much less success in matching the cross-section of stock prices and the level of stock prices across business cycles (through the risk-adjusted cost of equity). Nekrasov and Shroff (2009) obtain a similar result, suggesting the additional noise introduced in estimating the additional betas and risk premiums more than offsets the benefits of having more variables when it comes to matching observed stock prices.

\section{Insert Tables 3 and 4 about here}

The two tables show that all implementations of the standard valuation models, with a constant risk-adjusted cost of equity as the discount rate, yield valuations lower than the observed stock prices judged from the median VE (although the picture is more mixed judged from the mean VE). That is, even though analysts' forecasts of long-term growth rates (LTG) appear unreasonably high-together with a $3 \%$ growth rate of residual income in the

\footnotetext{
${ }^{21}$ As pointed out by Jorgensen et al. (2011), mean AVE, 15\% AVE, and 25\% AVE can yield a different ranking of models when the valuation error distribution has extreme values or skewedness. Twenty five percent AVE is also called interquartile range and has been used in the literature by Liu et al. (2002) and Jorgensen et al. (2011).
} 
continuing value for the CAPMG model - this does not translate into too high valuations. Hence, if LTG appears unreasonably high, the estimates of the risk-adjusted cost of equity must also be too high, and the error made in the risk adjustment in cost of equity more than offset the error in the forecasts of growth rates three to five years ahead.

Since over- and under-valuations may cancel in mean and median VE, our primary performance measure for valuation accuracy is the percentage median absolute valuation error (MAVE). Contrary to Nekrasov and Shroff (2009), we do not winsorize percentage absolute valuation errors at $100 \%$ to mitigate outliers but rather we consider these observations as genuine valuation errors. The implementation of the standard one-factor CAPM-based valuation model with 30 years of monthly returns for estimating the market risk premium yields the lowest MAVE for all three growth assumptions (CAPMC, CAPMG, and CAPMI), and the growth assumption of an annual growth rate of $3 \%$ in the continuing value (from year five) yields the lowest MAVE for all estimation periods for the market risk premium (5, 10, 20, 30, and all years). Hence, the CAPMG30 is the best performing implementation of the standard CAPM-based valuation model judged from the MAVE (35.9\%), and it is also the implementation of the model, which has the lowest under-valuation (median VE of $10.4 \%$ ), the lowest percentage of AVEs above $15 \%$ (77.7\%), and the lowest percentage of AVEs above 25\% (63.0\%). However, the CAPMG30 has a quite high standard deviation of AVEs compared to some of the other implementations, suggesting that there are some extreme observations. As noted above, the three-factor Fama-French model fares worse in terms of valuation accuracy for almost all implementations and performance measures (with a MAVE above $50 \%$ even for the best performing implementations).

The MAVE of $35.9 \%$ for the CAPMG30 standard one-factor CAPM is (in fact, exactly) the same as the reported MAVE for the implementation of this model by Nekrasov and Shroff (2009) based on firm-specific beta estimates (see their Table 2), even though their sampling of firms and sampling period are different from ours. Nekrasov and Shroff (2009) show that the MAVE can be reduced by up to five percentage points by using portfolio- or industryspecific beta estimates. This again suggests that estimation noise of betas and factor risk premiums is a significant concern in implementations of the standard approach of using an estimated risk-adjusted cost of equity for the valuation of individual stocks. Jorgensen et al. (2011) report mean AVE from 30\% - 40\% for their implementations of the standard residual income one-factor CAPM valuation model. Note, however, that their AVEs are reduced due to the fact that they apply a multiple valuation approach to correct for the models' under-valuation compared to observed stock prices (see their Tables 1 and 2). Our results for the valuation accuracy of standard CAPM-based valuation models thus largely confirm the results of prior research for our sampling of firms and our sampling period. 
The last two rows of Table 3 report the performance of two implementations of the CCAPM-based valuation model. The "CCAPM" implementation uses the term structure of interest rates for discounting and the associated forward rates for residual income calculations, whereas the "CCAPM-CIR" implementation uses the 10-year Treasury yield both for discounting and residual income calculations. Both implementations use a growth rate assumption for the risk-adjusted expected residual income returns in the continuing value such that both models produce a median VE, which is close to the median VE for the best implementation of the standard CAPM-based valuation models (10\%), i.e., the CAPMG30 model. This is done to provide a fair comparison of the CCAPM- and CAPM-based valuation models, i.e., such that the models have roughly the same level of under-valuation. This calibration yields growth rates of $\mu=-30 \%$ in the CCAPM implementation and $\mu=-60 \%$ in the CCAPM-CIR implementation.

The MAVE is almost the same for the CCAPM and the CCAPM-CIR implementations (25.4\% and $25.5 \%$, respectively), and the implementations also have nearly identical performance judged from the other performance measures, i.e., mean AVE, standard deviation of AVE, $15 \%$ AVE, and 25\% AVE. Hence, the only noticeable difference is in the growth rate assumption necessary to produce a median under-valuation of the same size as the CAPMG30 model. In the following discussion and analysis, we will only report results from the CCAPM implementation based on the term structure of interest rates since this is the more theoretically appealing model for properly taking account of the term premium.

Comparing the CCAPM and the standard CAPM-based valuation models, the CCAPMbased valuation model produces substantially better valuation accuracy than the standard CAPM-based valuation models. The MAVE is more than $40 \%$ higher for the best performing standard model (i.e., the CAPMG30 single-factor model) than for the CCAPM-based valuation model. The CCAPM model has also substantially better performance than the CAPMG30 model judged from the other performance measures, i.e., mean AVE, standard deviation of AVE, $15 \%$ AVE, and 25\% AVE.

In the above comparison of models, we have taken as given the growth rate of $g=3 \%$ in the CAPMG30 model on the basis of commonly used implementations of this model in the literature (such as in Nekrasov and Shroff 2009 and Jorgensen et al. 2011). Hence, this growth rate assumption is somewhat arbitrary. In our sample period from 1982 to 2008, the CAPMG30 model produces 10\% under-valuation suggesting that a growth rate of $3 \%$ is too low to match the level of stock prices. Table 5 reports the performance of the single-factor CAPMG30 and the CCAPM valuation models when the growth rates $g$ and $\mu$, respectively, are calibrated so as to minimize the square of the median VEs, such that each of the models 
match the level of stock prices. ${ }^{22}$

Insert Table 5 about here

The first two rows in Table 5 show the performance of the two models when the growth rates $g$ and $\mu$ are calibrated so as the minimize the squared median VE using the full sample of valuations from 1982 to 2008. While the MAVE is reduced for the CCAPM model (from $25.4 \%$ to 24.6\%), the MAVE actually increases for the standard CAPM-based valuation model (from 35.9\% to 38.9\%). Hence, if the models must match the level of stock prices over the full sample, the CCAPM valuation model fares even better compared to the CAPMG30 model. Note also that the growth rate $g$ for CAPMG30 has increased from $3 \%$ to an implied growth rate of $4.2 \%$, while the growth rate $\mu$ in CCAPM has increased from $-30 \%$ to $-11 \%$.

The results in the first two rows show the valuation accuracy of the models both in the cross-section and across the business cycles (bear and bull markets) through the 27 years of valuations. The last two rows in Table 5 show the results for a setting in which we only study the models' valuation accuracy in the cross-section. That is, we take the level of stock prices at each valuation date as given and calibrate the growth rates so as to minimize the squared median VEs at that valuation date. In that setting, the MAVE is reduced even further for the CCAPM model (from $25.4 \%$ to $23.2 \%$ ), while the MAVE is unchanged (35.9\%) for the standard CAPM-based model.

With calibrated growth rates, the MAVE in the standard CAPM-based valuation model is $58 \%$ higher than the MAVE in the CCAPM-based valuation model when the growth rates are calibrated using the full sample of valuations and $55 \%$ when the growth rates are calibrated for the valuations at each valuation date. In both calibration settings, the implied growth rates for the standard CAPM-based valuation model have increased from the $3 \%$ growth rate commonly used in the literature to $4 \%$ to $5 \%$, whereas the implied growth rates for the CCAPM valuation model are close to $\mu=-10 \%$. Hence, the calibrations of growth rates in order to match the level of stock prices yield high speculative growth rates in the standard CAPM-based valuation model, whereas the implied growth rates in the CCAPMbased valuation model are much more conservative. That is, the CCAPM-based valuation model fades the risk-adjusted expected residual income returns (i.e., the value creation) towards zero from year 12 with a rate of $10 \%$ per year. $^{23}$

\footnotetext{
${ }^{22}$ Note that this is very different from minimizing the median of the squared VEs or the MAVE.

${ }^{23}$ This does not imply the accounting is unbiased, i.e., expected unrecorded goodwill equal to zero (see Feltham and Ohlson 1995 and Feltham and Ohlson 1996). It only means the expected unrecorded goodwill has a limit equal to the limit of the risk adjustment for unrecorded goodwill. We cannot distinguish whether the fading of risk-adjusted expected value creation is due to lack of sustainable competitive advantages, reduced impact of conservative accounting in the long run, or simply due to counterbalancing the upward
} 
Summary results for the CCAPM model with yearly calibrations of growth rates are reported in Table 6. Again, we divide the results into the same three nine-year sub-periods and in the last column, we report the results for the full sample period. Of course, the MAVE of the entire sample period is the same as the MAVE in the last row of Table 5. The model produces very low valuation errors of $18.88 \%$ in the first sub-period, increasing to $25.88 \%$ in the last sub-period. This result must be seen in light of the fact that we have been very easy on sampling assumptions, i.e., we have not sorted out outliers (unlike, for example, Nekrasov and Shroff 2009 and Jorgensen et al. 2011) or companies without a long time-series of data (unlike, for example, Nekrasov and Shroff 2009), and still a 23.17\% MAVE is below any of their results for the standard CAPM-based model. This does not imply that the CCAPM model implemented in this article outperforms the fundamentals-based factor model considered in Nekrasov and Shroff (2009); only that it outperforms any version of the standard model considered in the literature using MAVE as the performance measure.

Insert Table 6 about here

Lines two to four show the estimated parameters in the industry panel estimation of the timeseries model for residual income returns (9), and the fifth line shows the calibrated growth rates in the continuing value. The estimated contemporaneous covariances between the innovations in the time-series models for residual income returns and the consumption index are relatively stable but at a low level from $0.01 \%$ to $0.03 \%$. This is reflected in small median net present values of the absolute values of risk adjustments reported in the sixth and seventh lines. These are very conservative estimates of the risk adjustments (at least compared to implied risk adjustments in the standard CAPM-based model). The results in lines eight to ten show that most of the book value premium is instead due to the net present values of expected future residual income returns. This is good news for the stock analyst! The stock analyst's time is better spent on generating forecasts of future earnings and book values than on trying to come to grips with betas, the market risk premiums, and very high speculative growth rates in the continuing value for the standard CAPM-based model. Of course, we can make the risk adjustment count more in the book value premium if we increase the assumed relative risk aversion of $\gamma=2$ to, for example, $\gamma=10$. However, untabulated results show that this reduces the valuation accuracy from a MAVE of $23.17 \%$ to a MAVE of $25.41 \%{ }^{24}$ In the asset pricing literature, the aggregate consumption series from the NIPA tables is well known to have too little variation to explain the observed historical average excess

bias in the analysts' long-term growth forecasts, the downward biased risk adjustments, or both (see below).

${ }^{24}$ Eliminating risk adjustments entirely from the CCAPM-based valuation model is not a viable approach either, since this increases both MAVE, 15\% AVE, and 25\% AVE. 
returns (over the short-term interest rate) for reasonable relative risk aversion parameters (i.e., the equity premium puzzle). However, even though this aggregated consumption series has many problems, our analysis shows that in terms of valuation accuracy, the CCAPMbased valuation model implemented with this series significantly outperforms the standard CAPM-based valuation model with a risk-adjusted cost of equity estimated on the basis of short or long time-series of historical stock returns.

\subsection{Investment strategy performance}

In this section, we change the perspective from an efficient market perspective to a fundamental valuation perspective: Can the two model types identify cheap and expensive stocks? That is, we now view the model prices as the stocks' fundamental values to which the market prices will eventually revert. If the models can indeed identify cheap and expensive stocks, this must be reflected in subsequent excess (abnormal and benchmark) returns on trading strategies based on a sorting of stocks according to their market pricing errors.

We take the best performing of the standard CAPM-based valuation models in terms of valuation accuracy, i.e., the one-factor CAPM model with an estimated risk premium based on 30 years of historical data and a constant growth rate after five years (i.e., the CAPMG30 model), and we compare it to the CCAPM-based valuation model. In both cases, we use yearly calibrations of growth rates to match the level of stock prices at each valuation date (cf., the last two rows of Table 5). That is, we only identify cheap and expensive stocks relative to the market level, and not whether the market level of stock prices is too low or too high at any given valuation date. The comparison is carried out in an investment strategy setup in which we construct portfolios based on the model implied market pricing errors and track their subsequent performance.

Our investment strategy setup is as follows. At each valuation date (i.e., at end of April each year from 1982 until 2008) and for each of the two valuation models, we estimate the model parameters based on historical data, and we calibrate the growth rates in each of the two models so as to minimize the squared median pricing error. In this setting, the percentage pricing error is calculated as $P E=(P-V) / V$, i.e., as a measure of how much the market price $P$ is off relative to its fundamental value $V$. We then sort for each valuation model the stocks according to their percentage pricing errors with the $30 \%$ lowest $P E$ stocks in a buy portfolio, the $30 \%$ highest $P E$ stocks in a sell portfolio, and the $40 \%$ middle $P E$ stocks in a hold portfolio (see Landsman et al. 2011 for a similar portfolio formation strategy). All three portfolios of stocks are equally weighted. We then track the out-of-sample performance of these three portfolios in up to five years, and we report the annualized average returns for 
each portfolio over the sample period of portfolio formations from 1982 to $2008 .^{25}$

We use a varied set of performance measures for our buy-and-hold investment strategies. Each of the three portfolios is a well-diversified portfolio (including more than 100 stocks each at each valuation date) and therefore our primary performance measure is the excess returns of the portfolios relative to the CRSP value-weighted market return, i.e., the excess return on portfolio $i$ over the holding period from portfolio formation date $t$ to date $t+\tau$ is given as

$$
E R_{t, t+\tau}^{i}=R_{t, t+\tau}^{i}-R_{t, t+\tau}^{M}
$$

where $R_{t, t+\tau}^{i}$ and $R_{t, t+\tau}^{M}$ are the realized compounded returns from $t$ to $t+\tau$ on portfolio $i$ and the value-weighted market index, respectively. ${ }^{26}$ The advantage of this performance measure is that it simply compares the realized returns on the portfolio to the realized return on the market index without using any estimated parameters.

However, the portfolios may have different exposures to risks. There are several ways of adjusting for risks. Although our results in the preceding section cast serious doubts on the use of beta-technologies, at least for valuation purposes, we follow the common approach in the literature, which is to adjust the returns for market risk or to adjust the returns for the three Fama-French risk factors. We calculate abnormal returns $A R_{t, t+\tau}^{i}$ on a portfolio $i$ over the holding period from $t$ to $t+\tau$ as

$$
A R_{t, t+\tau}^{i}=R_{t, t+\tau}^{i}-\left(R_{t, t+\tau}^{f}+\beta_{M K T}^{i}\left[R_{t, t+\tau}^{M}-R_{t, t+\tau}^{f}\right]+\beta_{S M B}^{i} R_{t, t+\tau}^{S M B}+\beta_{H M L}^{i} R_{t, t+\tau}^{H M L}\right)
$$

in the three factor case, and with $\beta_{S M B}^{i}=\beta_{H M L}^{i}=0$ and $\beta_{M K T}^{i}$ replaced by the market beta from the standard CAPM regression in the one-factor case. The betas are the factor portfolio betas $\beta_{j}^{i}$ estimated at the portfolio formation date. The (excess) returns on the factor portfolios are the realized compounded returns (relative to the zero-coupon return $R_{t, t+\tau}^{f}$ over the holding period from $t$ to $\left.t+\tau\right)$ on the factor portfolios.

Contrary to excess returns, abnormal returns depend critically on the estimated portfolio betas at the portfolio formation date. This dependence of the estimated betas is problematic when comparing the abnormal returns for the CAPMG30 valuation model across the three portfolios. The reason is that estimation errors in betas affect both the valuation of securities and, thereby, the allocation of securities to the buy, hold, and sell portfolios and

\footnotetext{
${ }^{25}$ As noted by Shumway (1997), it is important to take delisting returns into account. Stock returns and delisting returns are taken from CRSP. If a firm is delisted during the return period, the remaining return for the period is calculated by reinvesting in the value-weighted market portfolio. This mitigates concerns about survivorship bias. We apply a delisting return of $-100 \%$ for firms that are delisted for poor performance (CRSP delisting codes 500 and 520-584) if a delisting return is not available.

${ }^{26}$ In this notation, a holding period goes from the end of April in year $t$ to the end of April in year $t+\tau$.
} 
the subsequent realized abnormal returns. An under-estimated beta will over-estimate the CAPMG30 model price and, thus, stocks with under-estimated betas tend to be allocated to the buy portfolio, while stocks with over-estimated betas tend to be allocated to the sell portfolio, ceteris paribus. At the same time, the realized abnormal returns on the buy portfolio will be over-estimated due to under-estimated betas for stocks in that portfolio and, similarly, the realized abnormal returns on the sell portfolio will be under-estimated due to over-estimated betas for stocks in that portfolio. Hence, positive realized abnormal returns for the buy portfolio and negative realized abnormal returns for the sell portfolio may be "fake abnormal returns" caused by estimation errors in betas. Note that this is not an issue for the CCAPM valuation model, since the estimated betas used for calculating realized abnormal returns have no impact on the valuation of securities at the portfolio formation date and, thus, no impact on the allocation of securities into portfolios.

To overcome the beta estimation error problem in calculating abnormal returns for the CAPMG30 valuation model and to further investigate the impact of different risk exposures on abnormal returns, we also consider benchmark returns (see Daniel, Grinblatt, Titman, and Wermers 1997 and Wermers 2003) in which we compare subsequent realized returns on individual securities $k$ to realized returns on a portfolio $p$ matched on size, book-to-market, and momentum $(5 \times 5 \times 5)$ at the portfolio formation date, i.e.,

$$
B R_{t, t+\tau}^{k}=R_{t, t+\tau}^{k}-R_{t, t+\tau}^{p}, \quad k \in p
$$

The buy, hold, and sell portfolio realized benchmark returns are then calculated as the average of the realized benchmark returns on the securities allocated to each of the three portfolios at the portfolio formation date, i.e.,

$$
B R_{t, t+\tau}^{i}=\frac{1}{n_{i}} \sum_{k \in i} B R_{t, t+\tau}^{k}
$$

where $n_{i}$ is the number of securities allocated to portfolio $i=b u y$,hold, sell at the portfolio formation date $t .^{27}$

In the following two subsections, we consider average excess, abnormal, and benchmark returns on the three portfolios for buy-and-hold strategies, first for one-year holding periods and secondly for multi-year holding periods of up to five years. Subsequently, we consider

\footnotetext{
${ }^{27}$ At each valuation date (end of April each year), we use the stock assignments for our sample stocks to the DGTW benchmark portfolios (formed at the end of June the same year). The DGTW benchmarks are available via http://www.rhsmith.umd.edu/faculty/rwermers/ftpsite/Dgtw/coverpage.htm. These benchmark portfolios are redefined each year and, hence, we cannot use the benchmark returns on these portfolios also made available on this website. Instead, we calculate holding-period returns of up to five years directly on the benchmark portfolios formed in the valuation year.
} 
Sharpe and Sortino ratios as alternative performance measures, which do not rely on a particular model for risk adjustments (but only mean-risk preferences). We then show the results from a time-series analysis of the returns on a hedge strategy going long in the buy portfolio and taking a short position in the sell portfolio. We conclude with a statistical analysis in which we ask which of the two valuation models produce pricing errors having the highest explanatory power for subsequent excess returns relative to the Treasury yield.

\subsubsection{One-year holding period returns}

Figure 1 shows the average excess returns on the three portfolios formed based on the pricing errors from each of the two valuation models. We also show the average excess return of the CRSP equally weighted market index. For the CCAPM portfolios, there is a very clear pattern that the buy portfolio produces higher excess returns than the hold portfolio, which in turn produces higher excess returns than the sell portfolio. The latter has negative excess returns and is therefore an obvious candidate for a sell portfolio. The difference between the average excess returns for the buy and sell portfolios is $4.92 \%$ annually. The picture is more mixed for the CAPMG30 portfolios. In this case, the hold portfolio produces the highest average excess return, but still the buy portfolio produces higher average excess returns than the sell portfolio (with a difference equal to 1.72\%). For both valuation models, the sell portfolio is dominated by a positive average excess return on the CRSP equally weighted market index. The positive excess return on the equally weighted market index reflect the well-documented size effect that small cap stocks tend to provide higher returns than large cap stocks (first documented by Banz 1981). The buy portfolio for the CAPMG30 valuation model barely beats the equally weighted market index. ${ }^{28}$

Insert Figure 1 about here

While Figure 1 implies that both valuation models (more or less successfully) can identify cheap and expensive stocks judged from average excess returns, this analysis does not take into account that the three portfolios for each of the models may be exposed differently to various risk factors. Figure 2 shows the average abnormal returns when the one-factor CAPM

\footnotetext{
${ }^{28}$ Note that the CRSP equally weighted market index includes all US-listed stocks, whereas our sample of firms is much smaller and only includes relatively large firms due to our requirement of at least three April analysts' forecasts. For both valuation models, untabulated results show that the average size of the firms' equity values in the sample period from 1982 to 2008 is decreasing over the buy, hold, and sell portfolios, if the model values are used to calculate equity values. On the other hand, if the market prices of stocks are used to calculate equity values, then the ranking is reversed for both valuation models. Hence, our results do not seem to be driven by size (however defined) but rather genuinely by the differences between model values and market prices.
} 
is used for risk-adjusting returns, and Figure 3 shows the average abnormal returns when the three-factor Fama-French model is used for risk-adjusting returns. Both the CCAPM and the CAPMG30 valuation models clearly can identify cheap and expensive stocks judged from the abnormal returns based on the CAPM. The performance of the CAPMG30 model has increased significantly with CAPM abnormal returns compared to excess returns relative to the value-weighted market return. Both valuation models now produce a premium of around $4 \%$ to $5 \%$ between the buy and sell portfolios. However, with the Fama-French abnormal returns shown in Figure 3, both valuation models perform quite poorly both in terms of levels and in terms of ranking the portfolios: the premium between the buy and sell portfolios is down to less than $1 \%$, although still positive for both valuation models.

Insert Figures 2 and 3 about here

As noted above, the difference between the average abnormal returns on the buy and sell portfolios for the CAPMG30 valuation model may be "fake abnormal returns" due to the impact of estimation errors in betas on both the portfolio formation and the calculation of realized abnormal returns. Figure 4 shows the average benchmark returns for the two valuation models. As for the average excess returns shown in Figure 1, there is a very clear pattern in benchmark returns for the three CCAPM portfolios with a premium of $2.83 \%$ between the buy and sell portfolios. The impressive CAPM abnormal returns for the CAPMG30 valuation model in Figure 2 have been reduced to less than a $1 \%$ benchmark premium between the buy and sell portfolios, and the ranking of the portfolios is far from being impressive.

Insert Figure 4 about here

\subsubsection{Multi-year holding period returns}

A key principle of fundamental investing is that, although market prices of stocks might deviate from their fundamental values, there is no guarantee that market prices will come into line with fundamental values in the short run. The mispricing in the market may even get bigger before market prices eventually revert to their fundamental values. To capture this principle, we consider in this section holding-period returns of up to five years. As our performance measures, we use annualized average excess returns relative to the valueweighted market return, annualized average abnormal returns using both the one-factor CAPM and three-factor Fama-French models for risk adjustments as well as annualized average benchmark returns.

Figure 5 shows the annualized average excess returns for buy-and-hold investment strate- 
gies in the buy, hold, and sell portfolios based on the CCAPM and CAPMG30 valuation models, respectively, for holding periods from one year up to five years. The two valuation models provide similar results for holding periods longer than a year. The annualized average excess return of the buy portfolios are increasing with the investment horizon, while the sell portfolios have some tendency to revert to zero as the investment horizon increases. Note that, if mispriced stocks quickly revert to their fundamental values, for example, within a year, then one-year excess returns will be numerically large, but annualized excess returns would revert to zero for longer investment horizons. Hence, the results for both valuation models in Figure 5 suggest that significantly under-priced stocks are gradually reverting to fundamentals values but with large positive excess returns over long horizons, while significantly over-priced stocks more quickly revert to fundamental values. ${ }^{29}$

Insert Figure 5 about here

Figure 6 shows similar results when the annualized average holding-period returns are riskadjusted using the one-factor CAPM. Both valuation models show impressively stark results with an edge for the CAPMG30 over the CCAPM valuation model. Note that over-priced stocks now give large negative abnormal returns over long horizons. Figure 7 shows that both valuation models generally get the ranking between the buy, hold, and sell portfolios right when the returns are adjusted using the three-factor Fama-French model, although there is quite a variation over holding periods for both valuation models. On the other hand, while there is a (portfolio) theory that suggests that investors might care about excess return relative to the value-weighted market index or the CAPM abnormal returns, there is no theory suggesting that investors care about the three-factor Fama-French abnormal returns (unless the three factor portfolios proxy for some unmodeled state variables that investors care about in a multi-period investment setting).

Insert Figures 6 and 7 about here

Figure 8 shows the annualized average benchmark returns. There is a clear pattern for the CCAPM valuation model across all holding periods suggesting that this valuation model can indeed identify cheap and expensive stocks. The pattern is more mixed for the CAPMG30

\footnotetext{
${ }^{29}$ Untabulated results show that a sorting in decile portfolios produces significantly negative average excess and abnormal returns for the $10 \%$ lowest $P E$ portfolios for one-year holding periods but also that this portfolio is one of the best performing portfolios for longer holding periods. This supports the evidence that it might take some time for significantly under-priced stocks to revert to their fundamental values. The $10 \%$ highest $P E$ portfolios have significantly negative average excess and abnormal returns for all holding periods.
} 
valuation model.

Insert Figure 8 about here

Consistent with the principle of fundamental investing, long holding periods yield better performance on an annualized basis than shorter holding periods, independent of which valuation model is used for forming portfolios and which performance measure is used for measuring whether realized returns are higher or lower than should be expected.

\subsubsection{Sharpe and Sortino ratios}

The analysis of abnormal and benchmark returns in the preceding section is clearly subject to the criticism that we really do not know how we should risk-adjust holding-period returns, i.e., should we adjust by the single-factor CAPM, should we adjust by the three Fama-French factors, or should we adjust by benchmark portfolio returns matched on size, book-to-market, momentum, and even another fourth characteristic? In an investment setting, what does the individual investor consider to be abnormally high or low well-diversified portfolio returns? In this section, we consider two alternative performance measures, which essentially only assume that the investor has mean-risk preferences over the investment horizon. The Sharpe ratio (see Sharpe 1965) assumes that risk is measured as the volatility of the return, while the Sortino ratio (Sortino and Price 1994) assumes that risk is measured by the volatility of only downside returns, i.e., reflecting the preferences of a loss-averse investor.

The Sharpe ratio on a portfolio for a given holding period is calculated in the usual way as the annualized average (monthly) realized returns in excess of the zero-coupon return for the holding period divided by the annualized standard deviation of the (monthly) returns on the portfolio. Figure 9 shows the average Sharpe ratios on the buy, hold, and sell portfolios based on the CCAPM and CAPMG30 valuation models, respectively. Based on the Sharpe ratios, the buy portfolios clearly beat the sell portfolios using both valuation models for identifying cheap and expensive stocks, and they do so for both short and long holding periods. However, the buy and hold portfolios are consistently reversed for the CCAPM valuation model, while the CAPMG30 valuation model mostly gets the ranking right. In both cases, the differences between these two portfolios are small (as were also mostly the case for excess, abnormal, and benchmark returns in the preceding section).

\section{Insert Figure 9 about here}

It is not clear that the Sharpe ratio is a good measure for portfolio performance in an investment setting in which we wish to buy cheap stocks and sell expensive stocks. In such a setting, we want large and positive excess returns on the buy portfolio and numerically large 
negative excess returns on the sell portfolio. Hence, only one-sided risk should be penalized. The Sortino ratio has gained popularity recently, especially in the more practitioner-oriented literature (e.g., Pedersen and Satchell 2002, Estrada 2006, and Dias 2011). It is similar in nature to the Sharpe ratio in the sense that it adjusts excess returns for volatility. However, while the Sharpe ratio penalizes excess returns (relative to the risk-free return) equally for upside risk and downside risk, the Sortino ratio only penalizes for downside risk. We calculate the Sortino ratio on a portfolio over a given holding period as

$$
\text { Sortino ratio for portfolio } i=\frac{\bar{R}^{i}-T}{\sqrt{\frac{\sum_{j} I_{\left\{R_{t}^{i}<T\right\}}\left(R_{j}^{i}-T\right)^{2}}{N}}}
$$

where $\bar{R}^{i}$ is the annualized average monthly realized returns over the holding period, $T$ is the target return, which we chose to be the annualized zero-coupon return over the holding period, and the denominator is the target semideviation. Hence, the numerator is the same as in the Sharpe ratio, but the denominator is different. The target semideviation in the denominator is calculated almost as an estimate of a standard volatility, except we only

count the returns in the holding period which are less than the target, i.e., $I_{\left\{R_{j}^{i}<T\right\}}$ is the indicator function for annualized monthly returns lower than the target, and $N$ is the number of monthly returns observed in the holding period (see Sortino and der Meer 1991). Figure 10 shows the average Sortino ratios on the buy, hold, and sell portfolios based on the CCAPM and CAPMG30 valuation models, respectively. Both valuation models produce very convincing Sortino ratios for all holding periods (except for one-year holding periods in the CAPMG30 model). Hence, if the investor is only concerned about downside risk (loss aversion) relative to the risk-free return, both valuation models can clearly identify cheap and expensive stocks.

Insert Figure 10 about here

\subsubsection{Time-series analysis of hedge returns}

Based on the results in the preceding sections, an obvious hedge strategy would be to go long in the buy portfolio and short in the sell portfolio. However, the prior results are hampered by the fact that it requires a portfolio theory model to measure what is abnormally high or abnormally low returns on a portfolio strategy, but the underlying preference assumptions for the model (if there is a model) might not describe the individual investor's preferences well. In this section, we present time-series of unadjusted annualized realized holding-period returns on the above hedge strategy based on each of the two valuation models for forming portfolios. These strategies are based entirely on historical data at the portfolio formation 
dates and, thus, all realized returns are out-of-sample (as in the preceding sections).

Figures 11 and 12 show the time-series of annualized returns for holding periods of one, three, and five years on the hedge strategy based on the CCAPM and CAPMG30 valuation models, respectively. ${ }^{30}$ The various holding-period returns are shown relative to the year in which the hedge portfolio is initiated (i.e., the investment year). A hedge portfolio is formed at the valuation date each year from 1982 until 2008, and we are using portfolio returns from 1982 until 2013.

The hedge returns are large and positive in almost all investment years for both valuation models. The one-year holding-period strategies show greater volatility (as expected) than the three- and five-year holding-period strategies. However, note that the CAPMG30 three-year hedge strategy initated in 1997, i.e., the strategy covering the period from April 1997 until April 2000, has a huge negative realized return. On the other hand, if that portfolio is held for another two years, it is back on track with an annualized return over five years of $0.65 \%$. The average annualized realized returns (shown in the legends) are very high, especially for the CCAPM valuation model ranging from $4 \%$ to $5 \%$ per year. The comparable numbers for the CAPMG30 valuation model range from 1.5\% to $4.0 \%$ per year with the lowest average returns for the shorter term strategies. We should also note that all hedge strategies have negative returns for at least a few years (although they are all quite small for the longer-term hedge strategies based on the CCAPM valuation model). Hence, none of the two models provide valuations giving rise to genuine arbitrage strategies with only positive returns for a zero net investment.

\section{Insert Figures 11 and 12 about here}

It is also worth noting that the strategies do not seem to be negatively affected by economic/financial crises. In particular, for the crisis between 2000 and 2002, the strategies initiated in those years produce some of the highest returns, independent of the valuation model. Also considering the recent crisis in 2007 and 2008 does not give rise to significantly negative returns.

Figure 13 shows the Sharpe and Sortino ratios for the time-series of hedge returns in Figures 11 and 12 with a target return equal to zero (since the hedge strategy of a long position in the buy portfolio and a short position in the sell portfolio does not require any initial investment). The CCAPM valuation model performs better than the CAPMG30 valuation model for all holding periods using both performance measures. The Sortino ratio is especially relevant in this setting, since it only penalizes for downside risk (i.e., negative returns). Using this performance measure, there is a very clear picture that the CCAPM

\footnotetext{
${ }^{30}$ The time series of realized returns (and their averages) look very similar for the two- and four-year holding period hedge strategies but are omitted in graphs for expositional reasons.
} 
valuation model performs substantially better than the CAPMG30 valuation model and, consistent with the fundamental investment principle, the performance increases significantly with the length of the holding period.

\section{Insert Figure 13 about here}

\subsubsection{Statistical test of model selection for excess return predictability}

In the preceding sections, we evaluated the CCAPM and CAPMG30 valuation models by means of graphs and pictures (with no $t$-stats or $p$-values) of excess, abnormal, and benchmark realized portfolio returns based on the two models' predictions of whether particular stocks are under- or over-priced at valuation dates from 1982 to 2008. In this section, we perform a simple statistical test of the two models' relative ability to predict excess returns for individual stocks one-year-ahead relative to the risk-free one-year interest rate. To perform such an analysis, we must impose further statistical structure on the analysis.

We follow the approach taken by Dechow (1994) and apply a likelihood ratio test suggested by Vuong (1989) for comparing competing non-nested models. The test provides evidence concerning which of the two models are closer to the true data generating process. Consider the regressions (with time subscripts for valuation dates excluded)

$$
\begin{gathered}
\operatorname{Ex} R^{i}=a_{C C A P M}+b_{C C A P M} \beta_{C A P M}^{i}+c_{C C A P M} \frac{P^{i}}{V_{C C A P M}^{i}}+\varepsilon_{C C A P M}^{i}, \\
\varepsilon_{C C A P M}^{i} \sim \operatorname{NIID}\left(0, \sigma_{C C A P M}^{2}\right), \\
\operatorname{Ex} R^{i}=a_{C A P M}+b_{C A P M} \beta_{C A P M}^{i}+c_{C A P M} \frac{P^{i}}{V_{C A P M G 30}^{i}}+\varepsilon_{C A P M}^{i}, \\
\varepsilon_{C A P M}^{i} \sim \operatorname{NIID}\left(0, \sigma_{C A P M G 30}^{2}\right),
\end{gathered}
$$

where $\operatorname{Ex} R^{i}$ is the one-year-ahead excess return of asset $i$ relative to the one-year risk-free interest rate, $\beta_{C A P M}^{i}$ is the estimated one-factor CAPM beta on asset $i$ at the valuation date, $P^{i}$ is market price of asset $i$ at the valuation date, and $V_{C C A P M}^{i}$ and $V_{C A P M G 30}^{i}$ are the fundamental values of asset $i$ at the valuation date using the CCAPM and CAPMG30 valuation models, respectively. These regressions are standard CAPM-like regressions for whether the assets' pricing errors $P^{i} / V_{j}^{i}$ have explanatory power in addition to the assets' CAPM beta. (At this point, we have already lost faith in the Fama-French factors.) The

regressions imply that $\operatorname{Ex} R^{i} \sim N I I D\left(a_{j}+b_{j} \beta_{i, C A P M}+c_{j} \frac{P^{i}}{V_{j}^{i}}, \sigma_{j}^{2}\right)$ for valuation model $j=$ CCAPM, CAPMG30, and for valuation model $j$, the joint density of the observations across 
assets and valuation dates is

$$
f\left(R_{1}, \ldots, R_{n}\right)=\prod_{i=1}^{n} \prod_{t=1}^{T}\left(\frac{1}{2 \pi \sigma_{j}^{2}}\right)^{1 / 2} \exp \left\{-\frac{\left(e_{t, j}^{i}\right)^{2}}{2 \sigma_{j}^{2}}\right\}
$$

where $e_{t, j}^{i}=R_{t, j}^{i}-a_{j}-b_{j} \beta_{t}^{i}-c_{j} \frac{P_{t}^{i}}{V_{t, j}}$, and $t=1, \ldots, T$ are the valuation dates. The log-likelihood function is

$$
\log L\left(a_{j}, b_{j}, c_{j}, \sigma_{j}^{2}\right)=\sum_{i=1}^{n} \sum_{t=1}^{T}\left(-\frac{1}{2} \log \left(2 \pi \sigma_{j}^{2}\right)-\frac{\left(e_{t, j}^{i}\right)^{2}}{2 \sigma_{j}^{2}}\right) .
$$

The test statistic of interest for model selection is given by

$$
Z=\frac{1}{\sqrt{n T}} \frac{L R}{\widehat{\omega}} \stackrel{d}{\rightarrow} N(0,1)
$$

where

$$
\begin{aligned}
L R & =\log \left(\frac{L\left(\widehat{a}_{C A P M G 30}, \widehat{b}_{C A P M G 30}, \widehat{c}_{C A P M G 30}, \widehat{\sigma}_{C A P M G 30}^{2}\right)}{L\left(\widehat{a}_{C C A P M}, \widehat{b}_{C C A P M}, \widehat{c}_{C C A P M}, \widehat{\sigma}_{C C A P M}^{2}\right)}\right) \\
& =\frac{n T}{2}\left(\log \left(\widehat{\sigma}_{C C A P M}^{2}\right)-\log \left(\widehat{\sigma}_{C A P M G 30}^{2}\right)\right)+\frac{1}{2} \sum_{i=1}^{n} \sum_{t=1}^{T}\left(\frac{\left(e_{t, C C A P M}^{i}\right)^{2}}{\widehat{\sigma}_{C C A P M}^{2}}-\frac{\left(e_{t, C A P M G 30}^{i}\right)^{2}}{\widehat{\sigma}_{C A P M G 30}^{2}}\right),
\end{aligned}
$$

and

$$
\begin{aligned}
\widehat{\omega}^{2}=\frac{1}{n T} & \sum_{i=1}^{n} \sum_{t=1}^{T}\left(\log \left(\widehat{\sigma}_{C C A P M}^{2}\right)-\log \left(\widehat{\sigma}_{C A P M G 30}^{2}\right)+\frac{\left(e_{t, C C A P M}^{i}\right)^{2}}{2 \widehat{\sigma}_{C C A P M}^{2}}-\frac{\left(e_{t, C A P M G 30}^{i}\right)^{2}}{2 \widehat{\sigma}_{C A P M G 30}^{2}}\right)^{2} \\
& -\left(\frac{1}{n T} L R\right)^{2} .
\end{aligned}
$$

The test can conclude in favor of either valuation model. If the $Z$-statistic is positive and significant, the test indicates that the CAPMG30 valuation model is the better model, and if the $Z$-statistic is negative and significant, it indicates that the CCAPM valuation model is the better model in terms of providing pricing errors for predicting realized excess returns. The $Z$-statistic for our implementations of the CCAPM and CAPMG30 valuation models with calibrations of growth rates at each valuation date by the end of April each year is -2.4215 and a $p$-value of 0.0077 . Hence, at any conventional significance levels, the CCAPM valuation model produces pricing errors that can better able predict subsequent realized excess returns on individual stocks than the pricing errors generated from the CAPMG30 valuation model. This result is consistent with the graphical results in the preceding sections. 


\section{Conclusion}

Based on a large sample of firms and valuation dates, this article examines the empirical performance of standard valuation models (using an estimated firm-specific risk-adjusted cost of equity) and a CCAPM-based valuation model, in which expected future residual earnings are risk adjusted in the numerator and are then discounted with risk-free interest rates in the denominator. The empirical performance of the CCAPM-based valuation model is documented to be substantially better than any of the implemented standard one-factor CAPM and three-factor Fama-French models in terms of valuation accuracy in the crosssection and over business cycles. Moreover, in most dimensions, the CCAPM-based valuation model also beats the best performing standard model in terms of identifying cheap and expensive stocks measured by subsequent excess, abnormal, or benchmark returns of portfolio strategies based on the models' pricing errors. In statistical tests, the CCAPM is very significantly identified as the better model for predicting subsequent one-year-ahead excess returns relative to the risk-free interest rate even after controlling for beta risk. However, both types of models perform well from a fundamental valuation perspective, especially considering subsequent realized excess returns on buy-and-hold strategies for long holding periods (up to five years).

This article also documents the standard models require unreasonably high growth rates in continuing values of value creation for these models to match the level of stock prices when the cost of equity is estimated on the basis of historical stock returns. The CCAPM-based valuation model matches the level of stock prices with negative growth rates in the continuing values of value creation. This is consistent with economic theory suggesting positive NPV projects are expected to be competed away in the long run.

Our empirical analysis is based on analysts' consensus forecasts of firm-specific earnings growth. These forecasts have in prior literature been shown to be upwardly biased, especially for the reported long-term growth rates from three- to five-years-ahead. Nevertheless, a robustness check establishes that these overly optimistic long-term growth rates still contain useful information for the valuation of stocks in the cross-section.

In the CCAPM-based valuation model, forecasts of future residual income returns are also based on analysts' forecasts, but the risk adjustments are estimated from industry panel data based on a simple first-order autoregressive model for residual income returns and geometric Brownian motions for aggregate consumption and inflation. The forecasts of future residual income returns could also have been based on the time-series model of residual income returns. However, our choice of using analysts' forecasts is based on the assumption that analysts' forecasts are based on a much richer information set than the 
very simple time-series model. Given that it is often unclear exactly which earnings number analysts forecast, and the fact that long-term forecasts are very significantly upwardly biased, it would be a fruitful area of future research to build a more elaborate time-series model, which can be used for both forecasting and for determining risk adjustments. There is an emerging empirical literature developing primarily cross-sectional models for earnings predictions, and there is evidence that these models perform at least as well as analysts' forecasts in many dimensions (e.g., Hou, van Dijk, and Zhang 2012; Li, Richardson, and Tuna 2014; So 2013). Extending these models in the time-series dimension and including both firm- and industry characteristics and economy-wide measures of economic activity yield a more elaborate vector-autoregressive system, which can be used for both forecasting and for estimation of risk adjustments to expected future residual income.

The CCAPM-based valuation model is very conservative in the valuation of value creation in the continuing value with a median calibrated growth rate of $-10 \%$, and at the same time, it is very conservative in not making too large risk adjustments (cf., Table 6). Of course, these two results are interrelated. The conservatism in making risk adjustments does not come as a surprise given that we use the time-series of nondurable consumption from the NIPA tables as our proxy for aggregate consumption. It is this time-series that gives rise to the so-called equity premium puzzle.

Almost all articles in the equity premium puzzle literature assume constant equity premiums. However, Christensen and Feltham (2009) show the average historical excess return over the risk-free rate is likely to be an upwardly biased estimate of the risk-adjusted discount rate to be used in valuations if required expected rates of returns are stochastic and, in particular, if required expected rates of returns are countercyclical. There is overwhelming empirical evidence of countercyclical equity premiums (e.g., Cochrane 2005b), and also that most of the variation in equity prices is due to news about discount rates (in the order of $80 \%$ to $90 \%$, see Cochrane 2008) and not about future payoffs.

Maybe the nondurable aggregate consumption series from the NIPA tables is just a bad proxy for the part of investors' marginal utility of consumption which is correlated with the payoffs of equities and discount rates - maybe there is simply too much averaging and smoothing going into the construction of this series. Alternative proxies for aggregate consumption for pricing purposes have been used in the literature, such as the aggregate consumption-wealth ratio (Lettau and Ludvigson 2001), survey data for limited stock market participation (Malloy, Moskowitz, and Vissing-Jørgensen 2009), garbage data (Savov 2011), and many others. Alternative specifications of utility functions to the standard power utility function have also proved somewhat successful, such as habit formation (Campbell and Cochrane 1999), and recursive utility with long-run consumption risk (Bansal and Yaron 
2004). Developing better models of consumption-based asset pricing is a large and ongoing field in finance, but none of the attempts to improve the cross-sectional description of assets returns have yet evaluated the models in terms of matching the market prices of stocks in the cross-section and over business cycles or in terms of their performance from a fundamental valuation perspective, as we do in this article. This might be a fruitful area of future research.

\section{Appendix: Valuation of Alcoa Inc.}

In this appendix, we illustrate our implementation of the CCAPM-based valuation model. We value a specific company, Alcoa Inc., at a specific valuation date, April 15, 2002.

The valuation requires estimates of the persistence $\omega_{r}$ of residual income returns in the first-order autoregressive model (9) and the contemporaneous covariance $\sigma_{r a}$ between innovations in residual income returns and the innovations in the consumption index (10). These two parameters determine the risk adjustments to expected residual returns in (13). In our implementation of the valuation model in the text, the parameters are estimated using an industry panel estimation based on seven years of prior data at each valuation date (see point (d) in the CCAPM Model Procedure). However, for ease of presentation of the data in this appendix, we estimate these parameters based on data for Alcoa Inc. only, but based on 20 years of prior data.

\section{Insert Table 7 about here}

Table 7 shows the data and the data sources for the estimation of the residual income returns process (Panel A) and the consumption index process (Panel B) at April 15, 2002. The estimated parameters are $\omega_{r}=58.54 \%$ and $\sigma_{r a}=0.02 \%$. These estimated parameters are used for the valuation of Alcoa Inc. shown in Table 8.

\section{Insert Table 8 about here}

The valuation is based on the calibrated growth rate in the continuing value for matching the level of stock prices (see Table 5) in April 2002, $\mu=-7.05 \%$. The valuation yields an estimated value per share of 29.67 compared to a closing stock price of 36.71 on April 15, 2002. Hence, the model underestimates the market price with an absolute valuation error of $A V E=19.17 \%$ or the market overprices the stock compared to the fundamental value of the stock corresponding to a pricing error of $P E=23.72 \%$, depending on whether an efficient market perspective or a fundamental valuation perspective is used. 


\section{References}

Ang, A., and J. Liu (2004). How to discount cash flows with time-varying expected returns. The Journal of Finance 59(6), 2745-2783.

Bansal, R., and A. Yaron (2004). Risks for the long run: A potential resolution of asset pricing puzzles. The Journal of Finance 59, 1481-1509.

Banz, R. (1981). The relationship between return and market value of common stock. Journal of Financial Economics 9, 3-18.

Brennan, M. J. (2003). Corporate investment policy. In G. M. Constantinides, M. Harris, and R. Stulz (Eds.), Handbook of the Economics of Finance, pp. 167-214. Amsterdam: Elsevier.

Campbell, J. Y., and J. H. Cochrane (1999). By force of habit: A consumption-based explanation of aggregate stock market behavior. The Journal of Political Economy 107(2), 205-251.

Christensen, P. O., and G. A. Feltham (2003). Economics of Accounting: Volume I Information in Markets. New York: Springer Science+Business Media Inc. (Springer Series in Accounting Scholarship 1).

Christensen, P. O., and G. A. Feltham (2009). Equity valuation. Foundations and Trends in Accounting 4 (1), 1-112.

Ciccone, S. J. (2002). GAAP versus street earnings: Making earnings look higher and smoother. Accounting Enquiries 11(2), 155-186.

Claus, J., and J. Thomas (2001). Equity premia as low as three percent? Evidence from analysts' earnings forecasts for domestic and international stock markets. The Journal of Finance 56(5), 1629-1666.

Cochrane, J. H. (2005a). Asset Pricing. Princeton: Princeton University Press.

Cochrane, J. H. (2005b). Financial markets and the real economy. Foundations and Trends in Finance 1(1), 1-101.

Cochrane, J. H. (2008). The dog that did not bark: A defense of return predictability. The Review of Financial Studies 21(4), 1533-1575.

Daniel, K., M. Grinblatt, S. Titman, and R. Wermers (1997). Measuring mutual fund performance with characteristic-based benchmarks. The Journal of Finance 52(3), 1035-1058. 
Dechow, P. M. (1994). Accounting earnings and cash flows as measures of firm performance: The role of accounting accruals. Journal of Accounting and Economics 18(1), $3-42$.

Dias, A. (2011). The economic value of controlling for large losses in portfolio selection. Working paper, University of Warwick.

Dittmar, A. K. (2000). Why do firms repurchase stock? Journal of Business 73(3), 33155.

Easton, P. (2002). Using forecasts of earnings to simultaneously estimate growth and the rate of return on equity investment. Journal of Accounting Research 40(3), 657-676.

Estrada, J. (2006). Downside risk in practice. Journal of Applied Corporate Finance 18(1), $117-125$.

Fama, E. F., and K. R. French (1997). Industry costs of equity. Journal of Financial Economics 43(2), 153-193.

Fama, E. F., and K. R. French (2001). Disappearing dividends: Changing firm characteristics or lower propensity to pay? Journal of Financial Economics 60(1), 3-43.

Feltham, G. A., and J. A. Ohlson (1995). Valuation and clean surplus accounting for operating and financial activities. Contemporary Accounting Research 11(2), 689-731.

Feltham, G. A., and J. A. Ohlson (1996). Uncertainty resolution and the theory of depreciation measurement. Journal of Accounting Research 34(2), 209-234.

Feltham, G. A., and J. A. Ohlson (1999). Residual earnings valuation with risk and stochastic interest rates. The Accounting Review 74(2), 165-183.

Frankel, R., and C. Lee (1998). Accounting valuation, market expectation, and crosssectional stock returns. Journal of Accounting and Economics 25(3), 283-319.

Frazzini, A., and L. H. Pedersen (2014). Betting against beta. Journal of Financial Economics $111(1), 1-25$.

Gebhardt, W., C. Lee, and B. Swaminathan (2001). Toward an implied cost of capital. Journal of Accounting Research 39(1), 135-176.

Hermann, D. R., O. Hope, and W. B. Thomas (2008). International diversification and forecast optimism: The effect of Reg FD. Accounting Horizons 22(2), 179-197.

Hou, K., M. A. van Dijk, and Y. Zhang (2012). The implied cost of capital: A new approach. Journal of Accounting and Economics 53(3), 504-526. 
Jorgensen, B. N., Y. G. Lee, and Y. K. Yoo (2011). The valuation accuracy of equity value estimates inferred from conventional empirical implementations of the abnormal earnings growth model: U.S. evidence. Journal of Business Finance $\&$ Accounting 38(3-4), $446-471$.

Landsman, W. R., B. L. Miller, K. Peasnell, and S. Yeh (2011). Do investors understand really dirty surplus? The Accounting Review 86(1), 237-258.

Lettau, M., and S. Ludvigson (2001). Consumption, aggregate wealth and expected stock returns. The Journal of Finance 56(3), 815-849.

Levi, Y., and I. Welch (2014). Long-term capital budgeting. Working paper, University of California at Los Angeles.

Li, N., S. Richardson, and I. Tuna (2014). Macro to micro: Country exposures, firm fundamentals and stock returns. Journal of Accounting and Economics 58(1), 1-20.

Liu, J., D. Nissim, and J. Thomas (2002). Equity valuation using multiples. Journal of Accounting Research 40(1), 135-172.

Lundholm, R., and T. O'Keefe (2001). Reconciling value estimates from the discounted cash flow model and the residual income model. Contemporary Accounting Research 18(2), 311-335.

Malloy, C. J., T. J. Moskowitz, and A. Vissing-Jørgensen (2009). Long-run stockholder consumption risk and asset returns. The Journal of Finance 64(6), 2427-2479.

Mehra, R., and E. C. Prescott (1985). The equity premium: A puzzle. Journal of Monetary Economics 15(2), 145-161.

Miller, M. H., and F. Modigliani (1961). Dividend policy, growth, and the valuation of shares. The Journal of Business $34(4), 411-433$.

Nekrasov, A., and P. K. Shroff (2009). Fundamentals-based risk measurement in valuation. The Accounting Review 84(6), 1983-2011.

Nissim, D., and S. H. Penman (2001). Ratio analysis and equity valuation: From research to practice. Review of Accounting Studies 6(1), 109-154.

Ohlson, J. A. (1995). Earnings, book values, and dividends in security valuation. Contemporary Accounting Research 11(2), 661-687.

Ohlson, J. A., and B. Juettner-Nauroth (2005). Expected EPS and EPS growth as determinants of value. Review of Accounting Studies 10(2-3), 349-365.

Pedersen, C. S., and S. E. Satchell (2002). On the foundation of performance measures under asymmetric returns. Quantitative Finance 2(3), 217-223. 
Penman, S. H. (2001). On comparing cash flow and accrual accounting models for use in equity valuation: A response to Lundholm and O'Keefe. Contemporary Accounting Research 18(4), 681-692.

Penman, S. H. (2007). Financial Statement Analysis and Security Valuation (Third ed.). Boston: McGraw-Hill/Irwin.

Penman, S. H., and F. Reggiani (2013). Returns to buying earnings and book value: accounting for growth and risk. Review of Accounting Studies 18(4), 1021-1049.

Rubinstein, M. (1976). The valuation of uncertain income streams and the pricing of options. Bell Journal of Economics 7(2), 407-425.

Savov, A. (2011). Asset pricing with garbage. The Journal of Finance 66(1), 177-201.

Sharpe, W. F. (1965). Mutual fund performance. Journal of Business 39(1), 119-138.

Shumway, T. (1997). The delisting bias in CRSP data. The Journal of Finance 52(1), $327-40$.

So, E. C. (2013). A new approach to predicting analyst forecast errors: Do investors overweight analyst forecasts? Journal of Financial Economics 108(3), 615-640.

Sortino, F., and R. V. der Meer (1991). Downside risk. Journal of Portfolio Management $17(4), 27-75$.

Sortino, F. A., and L. N. Price (1994). Performance measurement in a downside risk framework. The Journal of Investing 3(3), 59-64.

Vuong, Q. H. (1989). Likelihood ratio tests for model selection and non-nested hypotheses. Econometrica 57(2), 307-333.

Wachter, J. A. (2006). A consumption-based model of the term structure of interest rates. Journal of Financial Economics 79(2), 365-399.

Wermers, R. (2003). Is money really "smart"? New evidence on the relation between mutual fund flows, manager behavior, and performance persistence. Working paper, University of Maryland. 
Table 1: Data sorting steps and their impact on the number of companies in the sample.

\begin{tabular}{lr}
\hline Sorting step and sorting criterion & \# companies left \\
\hline 1: Tickers in I/B/E/S with either one or two year or LTG forecasts & 16,918 \\
2: Sort out all forecasts not done in April & 16,067 \\
3: Sort out all forecasts of non-December earnings & 14,765 \\
4: Sort out all consensus estimates based on less than 3 analysts & 9,658 \\
5: Linking to Compustat and CRSP & 8,262 \\
6: Sort out all non-AMEX/NYSE/NASDAQ & 8,257 \\
7: Require both 1 and 2 year forecasts & 5,175 \\
8: Require 1, 2 and LTG forecasts & 3,377 \\
9: Delete companies with invalid IBCOM (net income) & 3,367 \\
10: Companies with positive CSE & 3,335 \\
11: Nonfinancial and non-utility & 2,526 \\
\hline
\end{tabular}

Note: The table takes the I/B/E/S database as starting point and then sorts out companies based on the listed criteria. The number of companies in the sample is measured by the number of distinct I/B/E/S tickers. The cibeslink macro available through WRDS is used to link the I/B/E/S and Compustat databases. The iclink macro available through WRDS provides the link to the CRSP dataset. Utilities are defined as companies with SIC codes 4900-4949 and financial firms as companies with SIC codes 6000-6999.

Table 2: Descriptive statistics of sample firms over three sub-periods.

\begin{tabular}{|c|c|c|c|c|c|c|c|c|}
\hline \multirow{2}{*}{$\begin{array}{l}\text { Model Inputs } \\
\text { Variables: }\end{array}$} & \multicolumn{2}{|c|}{$1982-1990$} & \multicolumn{2}{|c|}{ 1991-1999 } & \multicolumn{2}{|c|}{ 2000-2008 } & \multicolumn{2}{|c|}{ 1982-2008 } \\
\hline & Mean & Median & Mean & Median & Mean & Median & Mean & Median \\
\hline Price per share & 39.694 & 33.875 & 37.252 & 31.250 & 36.274 & 30.485 & 37.451 & 31.750 \\
\hline Book value per share & 25.565 & 18.248 & 16.857 & 10.793 & 19.822 & 10.163 & 20.099 & 11.692 \\
\hline Book-to-Market ratio & 0.683 & 0.536 & 0.509 & 0.376 & 0.625 & 0.350 & 0.596 & 0.396 \\
\hline Dividend payout & 0.324 & 0.319 & 0.239 & 0.188 & 0.149 & 0.000 & 0.224 & 0.170 \\
\hline ROE & 0.106 & 0.139 & 0.125 & 0.134 & 0.146 & 0.130 & 0.128 & 0.134 \\
\hline FROE one-year-ahead & 0.154 & 0.147 & 0.161 & 0.144 & 0.144 & 0.134 & 0.153 & 0.141 \\
\hline FROE two-years-ahead & 0.162 & 0.156 & 0.171 & 0.154 & 0.163 & 0.141 & 0.166 & 0.149 \\
\hline LTG & 0.133 & 0.120 & 0.152 & 0.140 & 0.163 & 0.150 & 0.152 & 0.140 \\
\hline Risk-free rate & 0.092 & 0.083 & 0.063 & 0.063 & 0.045 & 0.045 & 0.063 & 0.061 \\
\hline Cost of equity (CAPM) & 0.160 & 0.157 & 0.132 & 0.130 & 0.115 & 0.104 & 0.132 & 0.131 \\
\hline Cost of equity (FF) & 0.157 & 0.156 & 0.139 & 0.137 & 0.138 & 0.134 & 0.143 & 0.141 \\
\hline No. of observations & \multicolumn{2}{|c|}{2393} & \multicolumn{2}{|c|}{3696} & \multicolumn{2}{|c|}{3935} & \multicolumn{2}{|c|}{10024} \\
\hline
\end{tabular}

Note: The table shows mean and median firm-year values over three nine-year sub-periods. Price is on a per share basis at the valuation date. Book value is calculated from common shareholder equity in the beginning of the year of valuation. Dividend payout is calculated as the annual dividends divided by reported earnings. ROE is the return on equity calculated as reported earnings divided by end-of-year book value. FROE one-year-ahead (two-years-ahead) is forecasted return on equity calculated as analysts' one-year-ahead (two-years-ahead) forecast of net income in the month of April of each year divided by forecasted end-of-year book value per share. Book value per share is forecasted through the clean surplus relation assuming a constant dividend payout ratio. LTG is analysts' forecasts of the long-term growth rate in EPS. The risk-free rate is the 10-year US Treasury yield. Cost of equity (CAPM) is the cost of equity, calculated using CAPM (equation (15) with $\beta_{S M B}=\beta_{H M L}=0$ ). Cost of equity (FF) is the cost of equity calculated using the Fama-French three-factor model (equation (15)). 
Table 3: Performance meassure results for the standard valuation model using the one-factor CAPM-based risk-adjusted cost of equity compared to the CCAPM valuation model.

\begin{tabular}{|c|c|c|c|c|c|c|c|c|}
\hline & \multicolumn{3}{|c|}{ VE } & \multicolumn{5}{|c|}{ AVE } \\
\hline CAPM one factor: & Mean & Median & S.D. & Mean & Median & S.D. & $15 \% A V E$ & $25 \% A V E$ \\
\hline CAPMCAll & 0.290 & 0.404 & 0.504 & 0.495 & 0.462 & 0.335 & 0.877 & 0.783 \\
\hline CAPMC5 & -0.111 & 0.423 & 1.456 & 0.919 & 0.596 & 1.144 & 0.916 & 0.851 \\
\hline CAPMC10 & 0.262 & 0.433 & 0.604 & 0.558 & 0.521 & 0.375 & 0.900 & 0.814 \\
\hline CAPMC20 & 0.218 & 0.306 & 0.528 & 0.463 & 0.407 & 0.362 & 0.821 & 0.697 \\
\hline CAPMC30 & 0.170 & 0.282 & 0.560 & 0.451 & 0.372 & 0.397 & 0.819 & 0.682 \\
\hline CAPMGAll & 0.071 & 0.288 & 0.781 & 0.556 & 0.432 & 0.570 & 0.850 & 0.735 \\
\hline CAPMG5 & -0.393 & 0.319 & 1.829 & 1.089 & 0.586 & 1.527 & 0.895 & 0.818 \\
\hline CAPMG10 & -0.015 & 0.331 & 1.024 & 0.699 & 0.511 & 0.761 & 0.879 & 0.790 \\
\hline CAPMG20 & -0.029 & 0.134 & 0.792 & 0.543 & 0.404 & 0.594 & 0.799 & 0.667 \\
\hline CAPMG30 & -0.124 & 0.104 & 0.881 & 0.560 & 0.359 & 0.705 & 0.777 & 0.630 \\
\hline CAPMIAll & 0.488 & 0.565 & 0.357 & 0.578 & 0.584 & 0.227 & 0.950 & 0.908 \\
\hline CAPMI5 & 0.345 & 0.574 & 0.790 & 0.698 & 0.623 & 0.525 & 0.952 & 0.915 \\
\hline CAPMI10 & 0.473 & 0.578 & 0.419 & 0.600 & 0.605 & 0.244 & 0.949 & 0.909 \\
\hline CAPMI20 & 0.453 & 0.529 & 0.373 & 0.552 & 0.553 & 0.244 & 0.935 & 0.878 \\
\hline CAPMI30 & 0.430 & 0.511 & 0.391 & 0.541 & 0.533 & 0.252 & 0.935 & 0.880 \\
\hline CCAPM: & & & & & & & & \\
\hline CCAPM & -0.044 & 0.091 & 0.621 & 0.377 & 0.254 & 0.509 & 0.694 & 0.507 \\
\hline CCAPM-CIR & -0.037 & 0.094 & 0.608 & 0.373 & 0.255 & 0.494 & 0.700 & 0.508 \\
\hline
\end{tabular}

Note: The table presents the mean, median, and standard deviation of the percentage valuation errors $(P-V) / P$ and of the absolute percentage valuation errors $|P-V| / P$. 15\% AVE (25\% AVE) shows the percentage of companies for which the valuation error is larger than $15 \%(25 \%)$. All valuations for the standard model are based on the one-factor CAPM cost of equity. CAPMC stands for constant RI, CAPMG for growth in RI, and CAPMI for industry growth in the continuing value. The number in the model name in each row of the first column indicates the number of years over which the factor risk premium is calculated, and "All" stands for using all historical data, i.e., data since 1926. The last two rows show the results for the CCAPM model using the term structure of interest rates (CCAPM) and using a constant interest rate equal to the 10-year Treasury yield (CCAPM-CIR), respectively.

Table 4: Performance measure results for the standard valuation model using the three-factor Fama-French based risk-adjusted cost of equity.

\begin{tabular}{|c|c|c|c|c|c|c|c|c|}
\hline & \multicolumn{3}{|c|}{ VE } & \multicolumn{5}{|c|}{ AVE } \\
\hline FF three factors & Mean & Median & S.D. & Mean & Median & S.D. & $15 \% A V E$ & $25 \% A V E$ \\
\hline FFCAll & 0.255 & 0.464 & 0.767 & 0.608 & 0.542 & 0.551 & 0.903 & 0.825 \\
\hline FFC5 & -0.107 & 0.453 & 1.535 & 0.944 & 0.633 & 1.223 & 0.915 & 0.854 \\
\hline FFC10 & 0.108 & 0.448 & 1.088 & 0.723 & 0.573 & 0.831 & 0.904 & 0.832 \\
\hline FFC20 & 0.031 & 0.396 & 1.157 & 0.730 & 0.550 & 0.909 & 0.890 & 0.802 \\
\hline FFC30 & 0.053 & 0.370 & 1.071 & 0.679 & 0.514 & 0.841 & 0.881 & 0.790 \\
\hline FFGAll & 0.027 & 0.370 & 1.109 & 0.705 & 0.525 & 0.867 & 0.881 & 0.797 \\
\hline FFG5 & -0.433 & 0.360 & 2.002 & 1.169 & 0.639 & 1.688 & 0.910 & 0.846 \\
\hline FFG10 & -0.202 & 0.350 & 1.569 & 0.914 & 0.576 & 1.298 & 0.890 & 0.819 \\
\hline FFG20 & -0.322 & 0.270 & 1.641 & 0.958 & 0.568 & 1.377 & 0.882 & 0.805 \\
\hline FFG30 & -0.285 & 0.239 & 1.518 & 0.880 & 0.522 & 1.276 & 0.869 & 0.776 \\
\hline FFIAll & 0.470 & 0.597 & 0.511 & 0.632 & 0.624 & 0.319 & 0.955 & 0.921 \\
\hline FFI5 & 0.326 & 0.589 & 0.893 & 0.733 & 0.649 & 0.622 & 0.955 & 0.914 \\
\hline FFI10 & 0.384 & 0.588 & 0.729 & 0.678 & 0.634 & 0.488 & 0.951 & 0.910 \\
\hline FFI20 & 0.345 & 0.563 & 0.746 & 0.667 & 0.617 & 0.499 & 0.942 & 0.893 \\
\hline FFI30 & 0.360 & 0.552 & 0.699 & 0.643 & 0.596 & 0.472 & 0.945 & 0.897 \\
\hline
\end{tabular}

Note: The table presents the mean, median, and standard deviation of the percentage valuation errors $(P-V) / P$ and of the absolute percentage valuation errors $|P-V| / P$. 15\% AVE (25\% AVE) shows the percentage of companies for which the valuation error is larger than $15 \%(25 \%)$. All valuations for the standard model are based on the Fama-French three-factor cost of equity. FFC stands for constant RI, FFG for growth in RI, and FFI for industry growth in the continuing value. The number in the model name in each row of the first column indicates the number of years over which the factor risk premiums are calculated, and "All" stands for using data all historical data, i.e., data since 1926. 
Table 5: Performance measure results for the standard valuation model using the one-factor CAPM-based risk-adjusted cost of equity compared to the CCAPM valuation model using calibrated growth rates.

\begin{tabular}{|c|c|c|c|c|c|c|c|c|c|}
\hline & Growth rate & \multicolumn{3}{|c|}{ VE } & \multicolumn{5}{|c|}{ AVE } \\
\hline Cal. full sample & & Mean & Median & S.D. & Mean & Median & S.D. & $15 \% A V E$ & $25 \% A V E$ \\
\hline CAPMG30 & $g=0.042$ & -0.314 & -0.007 & 1.072 & 0.677 & 0.389 & 0.899 & 0.779 & 0.650 \\
\hline CCAPM & $\mu=-0.110$ & -0.159 & 0.000 & 0.709 & 0.407 & 0.246 & 0.612 & 0.677 & 0.493 \\
\hline Cal. each year & & & & & & & & & \\
\hline CAPMG30 & $g=0.050$ & -0.205 & -0.008 & 0.886 & 0.565 & 0.359 & 0.725 & 0.764 & 0.626 \\
\hline CCAPM & $\mu=-0.100$ & -0.146 & -0.004 & 0.687 & 0.389 & 0.232 & 0.595 & 0.658 & 0.472 \\
\hline
\end{tabular}

Note: The table presents the mean, median, and standard deviation of the percentage valuation errors $(P-V) / P$ and of the absolute percentage valuation errors $|P-V| / P$. 15\% AVE (25\% AVE) shows the percentage of companies for which the valuation error is larger than $15 \%(25 \%)$. All valuations for the standard model (CAPM) are based on the one-factor CAPM cost of equity with the market risk premium estimated over 30 years prior to the valuations and a growth rate in residual income equal to $g$ from year 5. All valuations for the CCAPM model using the term structure of interest rates assume a growth rate of risk-adjusted expected residual income returns equal to $\mu$ from year 12 . In the first two rows, the growth rates $g$ and $\mu$ are calibrated using the full sample of valuations so as to minimize the (squared) median VE, while the results in the last two rows follow from calibrating the growth rates within each year's valuations so as to minimize the (squared) median VE for that year. The reported growth rates in the last two rows are median implied growth rates for the 27 years of valuations.

Table 6: Summary results for the CCAPM valuation model with yearly calibrations of growth rates.

\begin{tabular}{|c|c|c|c|c|}
\hline & 1982-1990 & 1991-1999 & 2000-2008 & 1982-2008 \\
\hline & Median & Median & Median & Median \\
\hline AVE & 0.1888 & 0.2496 & 0.2588 & 0.2317 \\
\hline$R I R^{o}$ & 0.0152 & 0.0035 & -0.0228 & 0.0020 \\
\hline$\omega_{r}$ & 0.6106 & 0.5837 & 0.5380 & 0.5697 \\
\hline$\sigma_{r a}$ & 0.0002 & 0.0001 & 0.0003 & 0.0002 \\
\hline$\mu$ & -0.0900 & -0.0800 & -0.1300 & -0.1000 \\
\hline RA $1-12$ & 0.0064 & 0.0062 & 0.0174 & 0.0092 \\
\hline RA CV & 0.0041 & 0.0056 & 0.0264 & 0.0097 \\
\hline RIR $1-5$ & 0.3655 & 0.5867 & 0.6834 & 0.5682 \\
\hline RIR 6-12 & 0.3693 & 0.6894 & 0.8917 & 0.6682 \\
\hline RIR CV & 0.1923 & 0.4323 & 0.3659 & 0.3423 \\
\hline No. of valuations & 2394 & 3697 & 3936 & 10,027 \\
\hline
\end{tabular}

Note: The table shows median values of the performance and key elements of the valuation using the CCAPM model with the term structure of interest rates and yearly calibrations of the growth rate in the continuing value. AVE are the absolute valuation errors, $|P-V| / P$. VE are the valuation errors, $(P-V) / P$. RIR is the estimated structural industry level of residual income returns $R I R . \sigma_{r}$ is the estimated industry $\operatorname{AR}(1)$ coefficient, $\sigma_{r a}=\operatorname{Cov}(\varepsilon, \delta)$, and $\mu$ is the implied growth rate in the continuing value. RA 1-12 is the sum of discounted absolute risk adjustments for periods 1-12. RA TV is the discounted continuing value of absolute risk adjustments. RIR $1-5$ is the sum of discounted $R I R$ for period $1-5$. RIR $6-12$ is the sum of discounted $R I R$ for periods $6-12$. RIR CV is the discounted continuing value of RIR. The final row shows the number of valuations in each sub-period. 


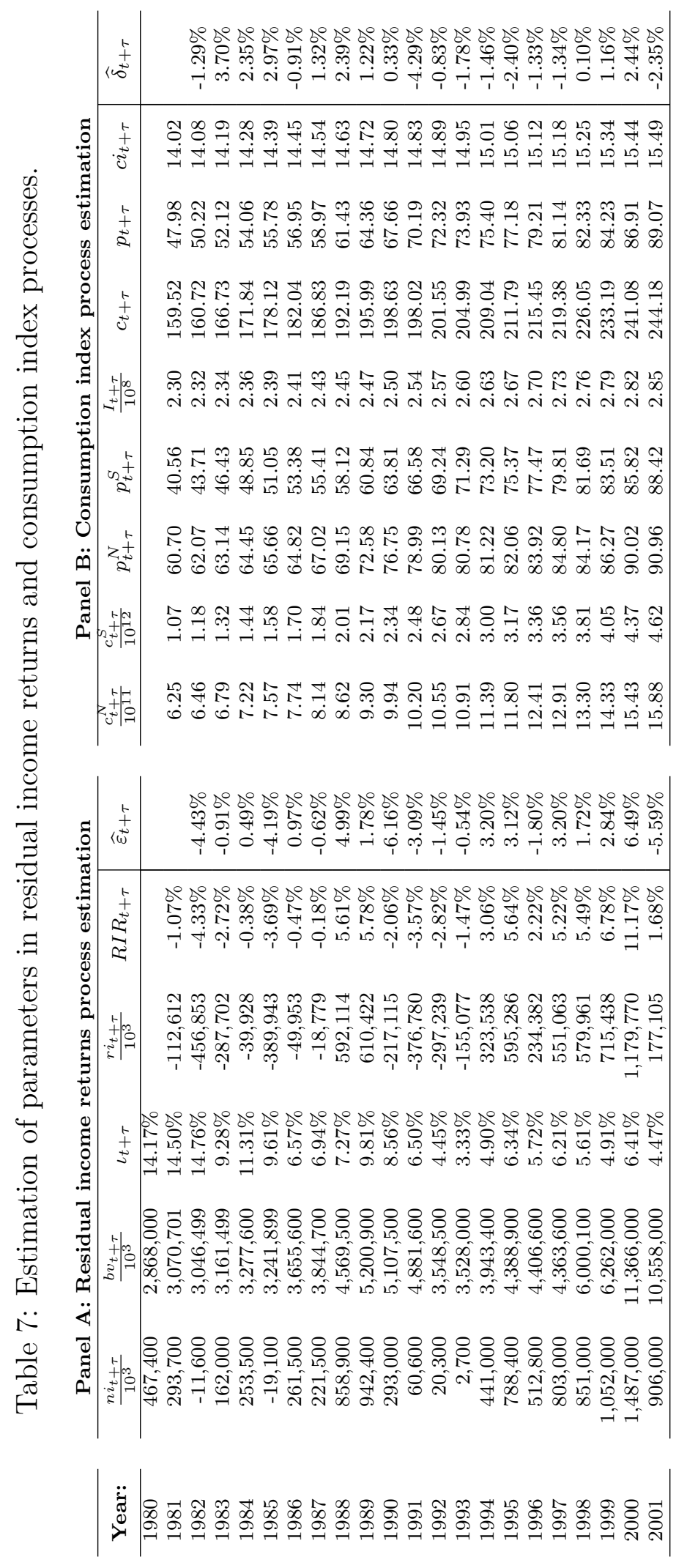

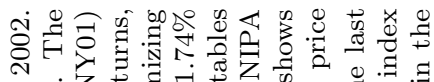

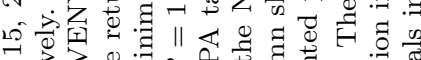

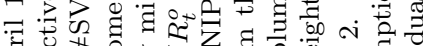

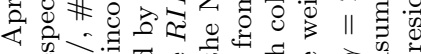

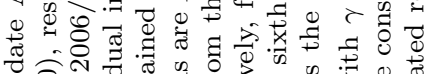

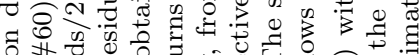

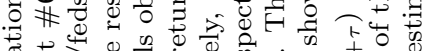

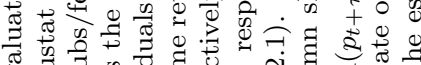

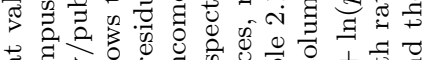

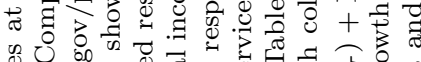

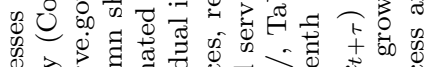

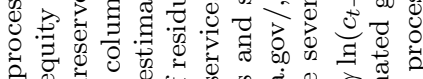
20.

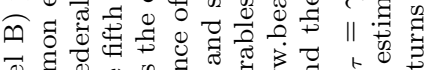
过

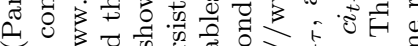

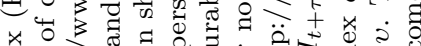

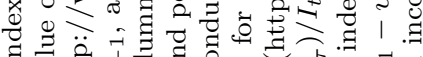

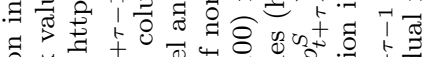

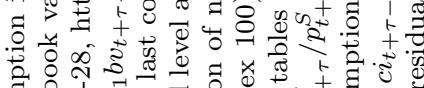

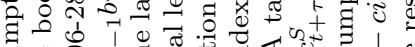

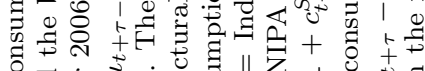

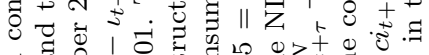
들

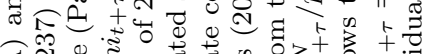

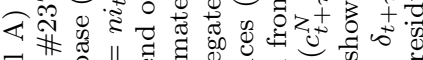
可

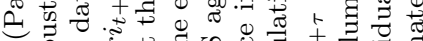

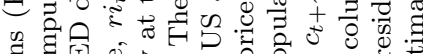

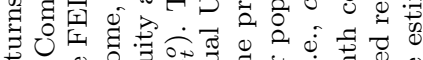

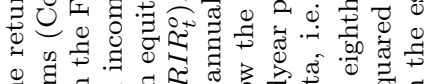

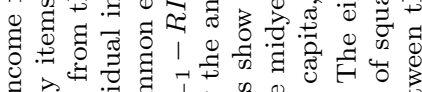

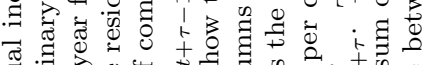

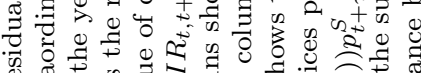

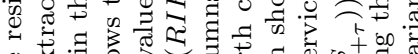

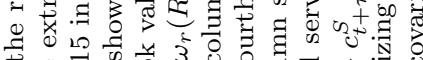
녕

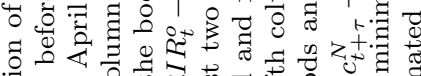

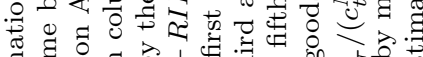

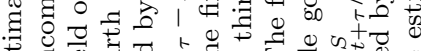

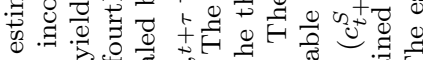

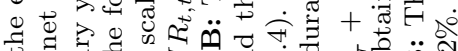

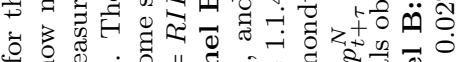
क

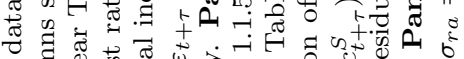
$\circ$ 年

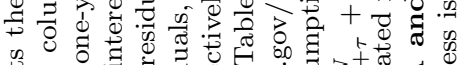

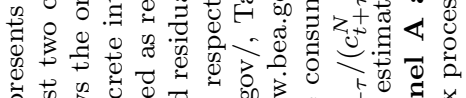

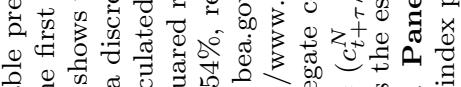

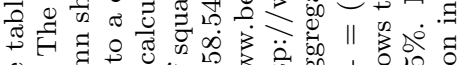

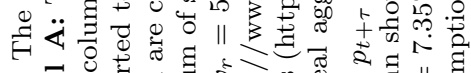

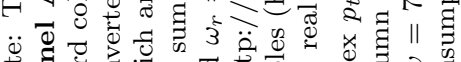

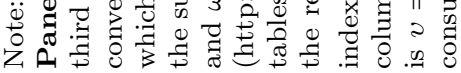




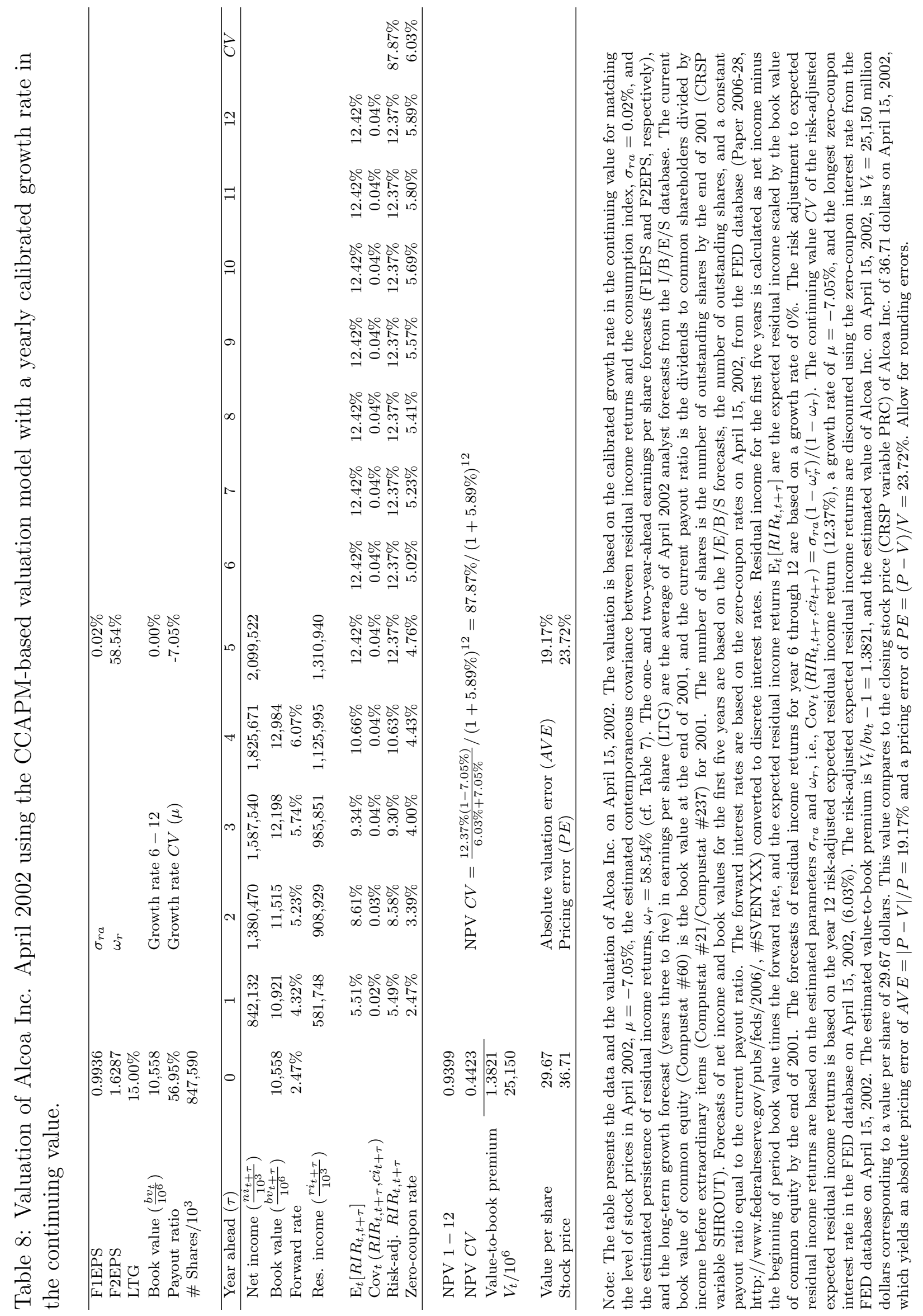




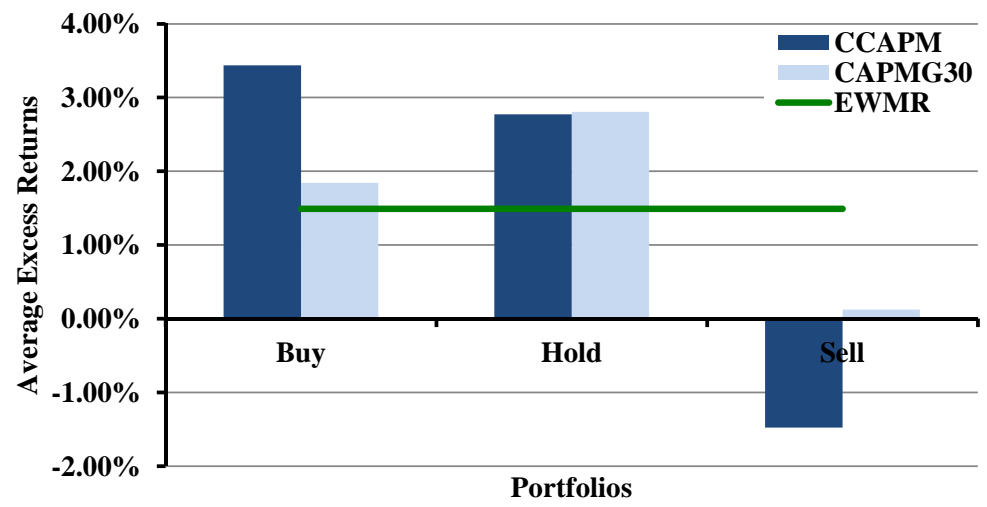

Figure 1: One-year average portfolio returns in excess of the value-weighted market return for both the CCAPM and the CAPMG30 valuation models as well as for the equally weighted market return (EWMR).

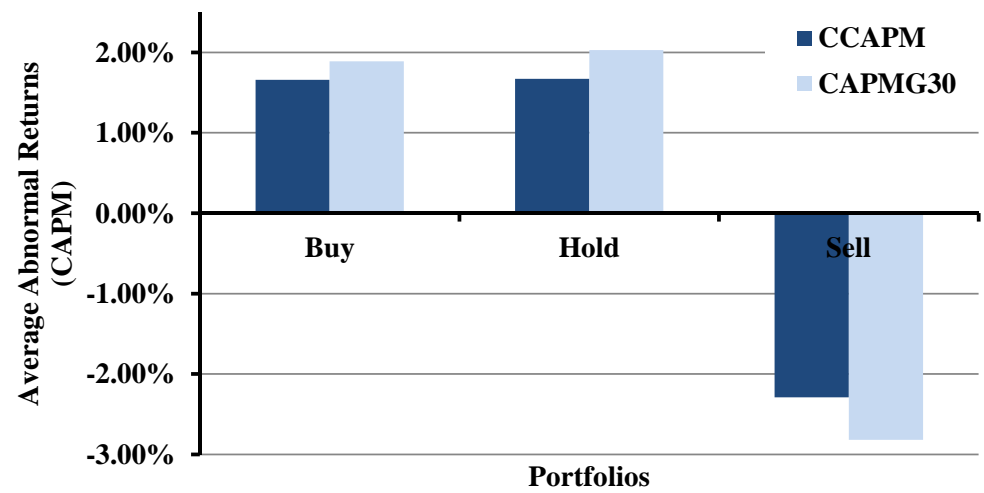

Figure 2: One-year average abnormal portfolio returns for both the CCAPM and the CAPMG30 valuation models. Risk adjustments are based on the one-factor CAPM.

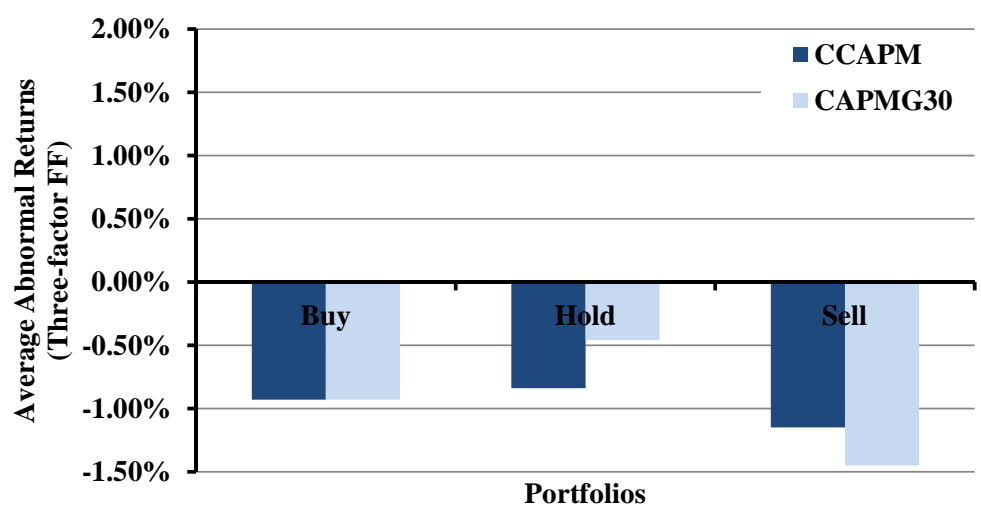

Figure 3: One-year average abnormal portfolio returns for both the CCAPM and the CAPMG30 valuation models. Risk adjustments are based on the three-factor Fama-French model. 


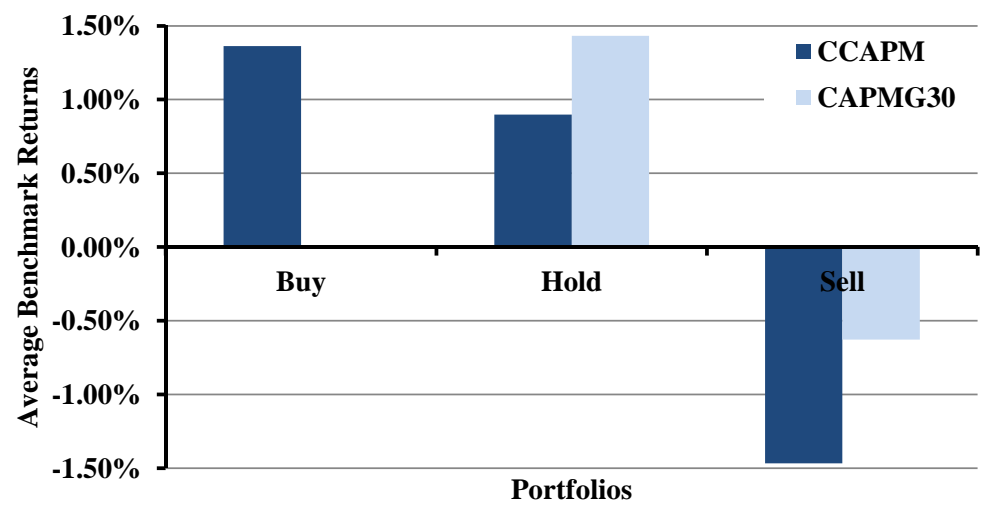

Figure 4: One-year average benchmark portfolio returns for both the CCAPM and the CAPMG30 valuation models.
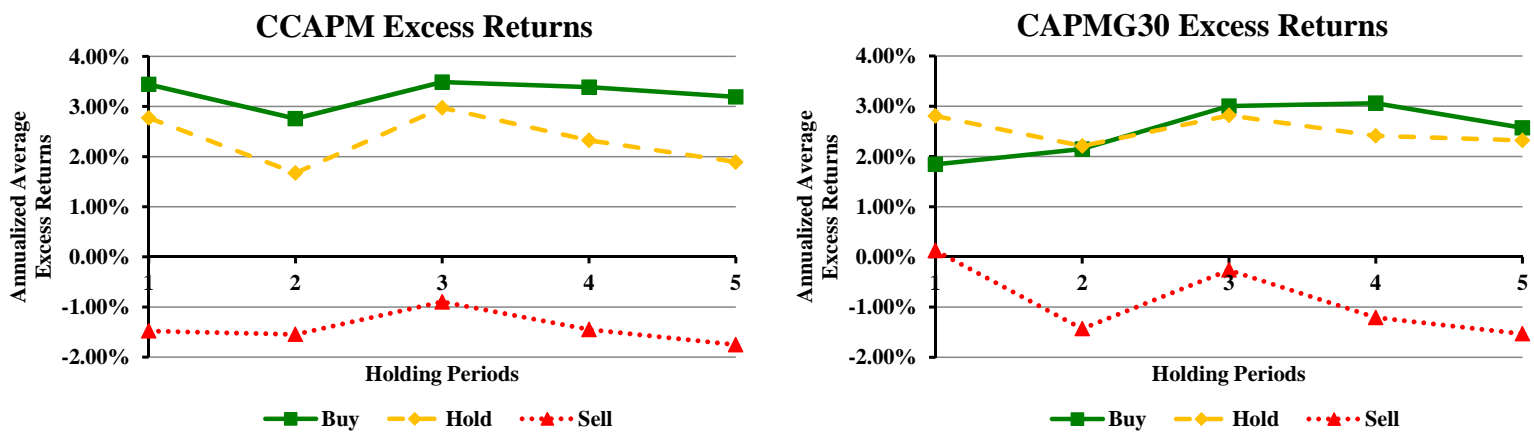

Figure 5: One- to five-year annualized average excess returns on the buy, hold, and sell portfolios based on the CCAPM and CAPMG30 valuation models, respectively.
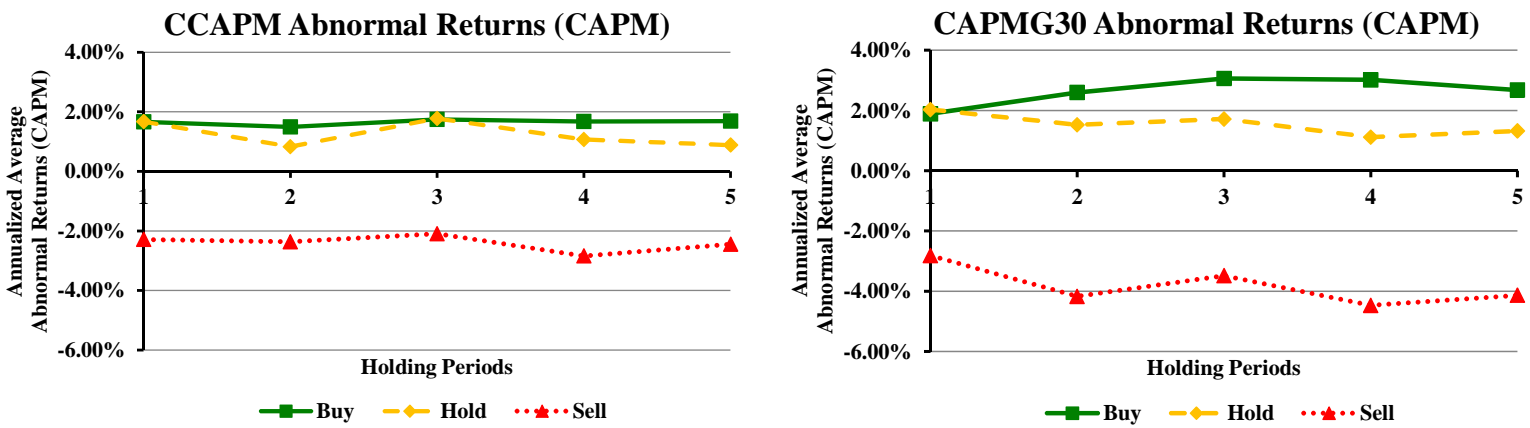

Figure 6: One- to five-year annualized average abnormal returns on the buy, hold, and sell portfolios based on the CCAPM and CAPMG30 valuation models, respectively. Risk adjustments are based on the one-factor CAPM. 

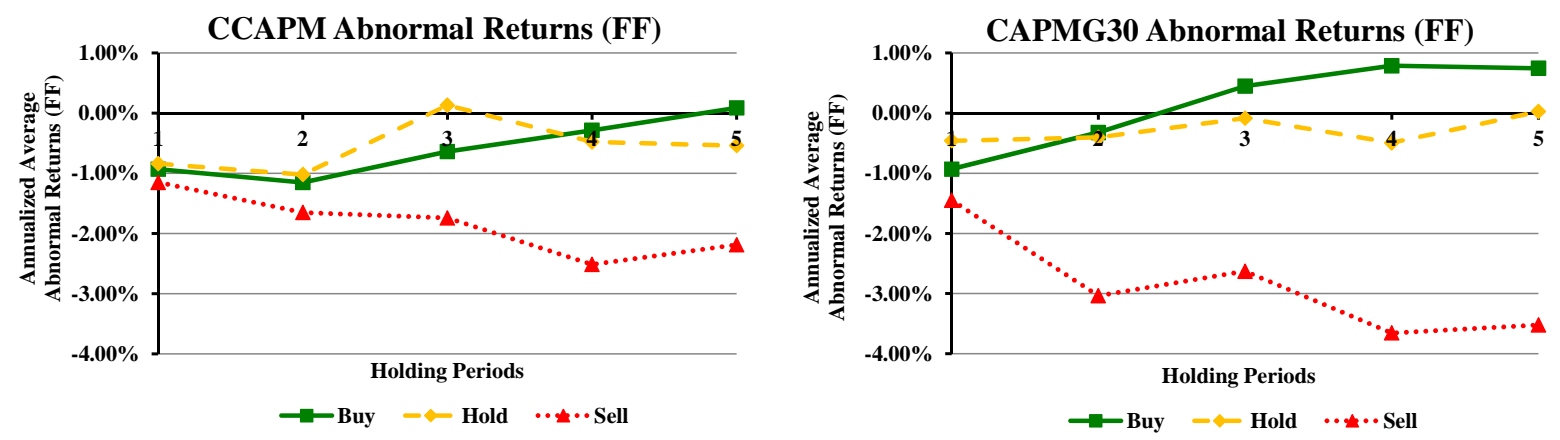

Figure 7: One- to five-year annualized average abnormal returns on the buy, hold, and sell portfolios based on the CCAPM and CAPMG30 valuation models, respectively. Risk adjustments are based on the three-factor Fama-French model.
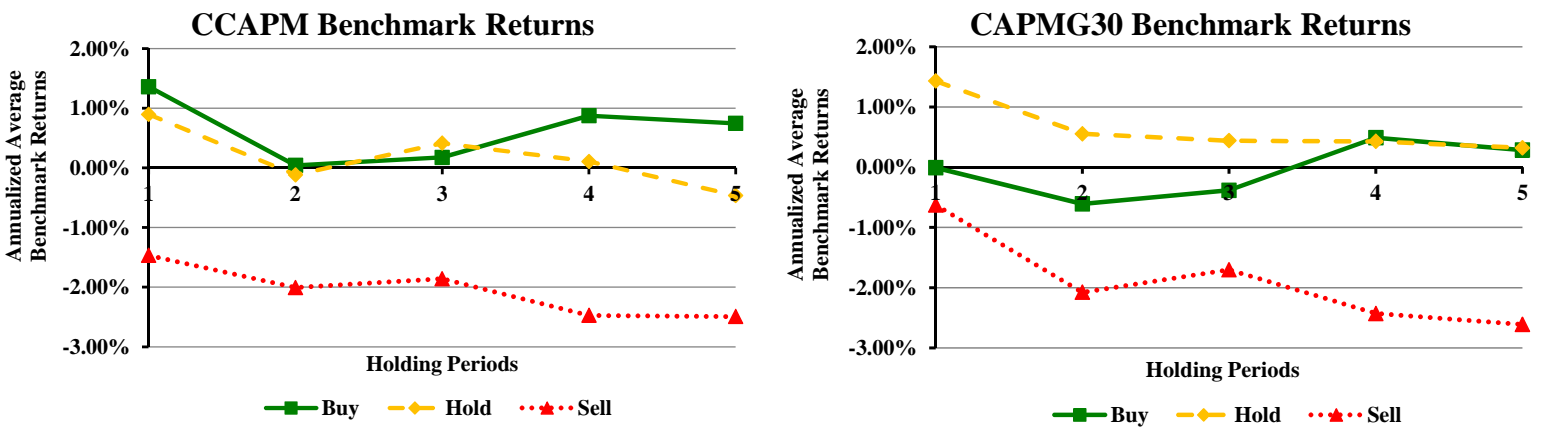

Figure 8: One- to five-year annualized average benchmark returns on the buy, hold, and sell portfolios based on the CCAPM and CAPMG30 valuation models, respectively.
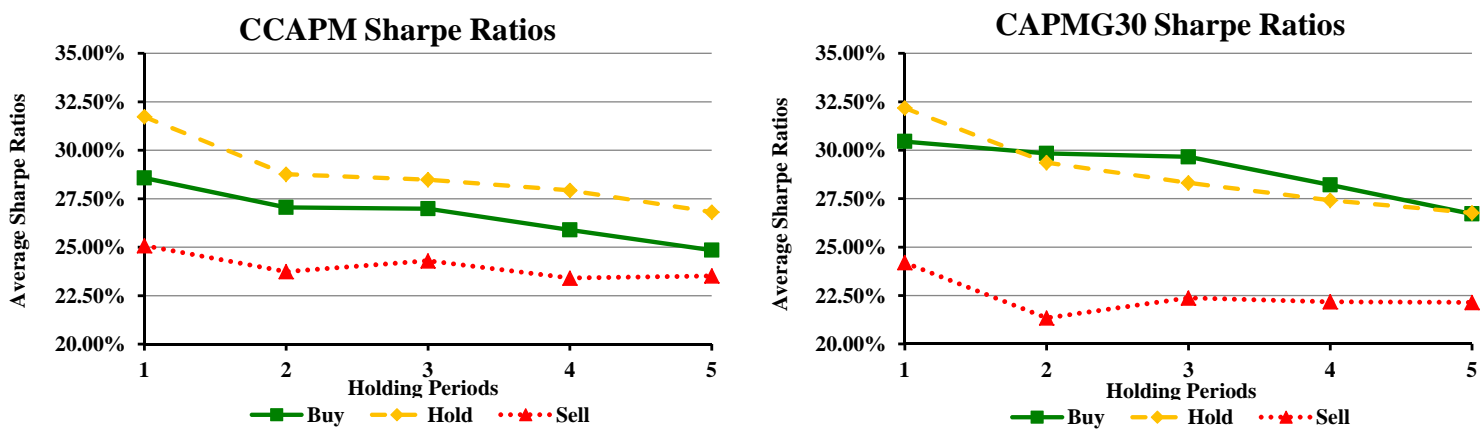

Figure 9: One- to five-year average annualized Sharpe ratios on the buy, hold, and sell portfolios based on the CCAPM and CAPMG30 valuation models, respectively. 

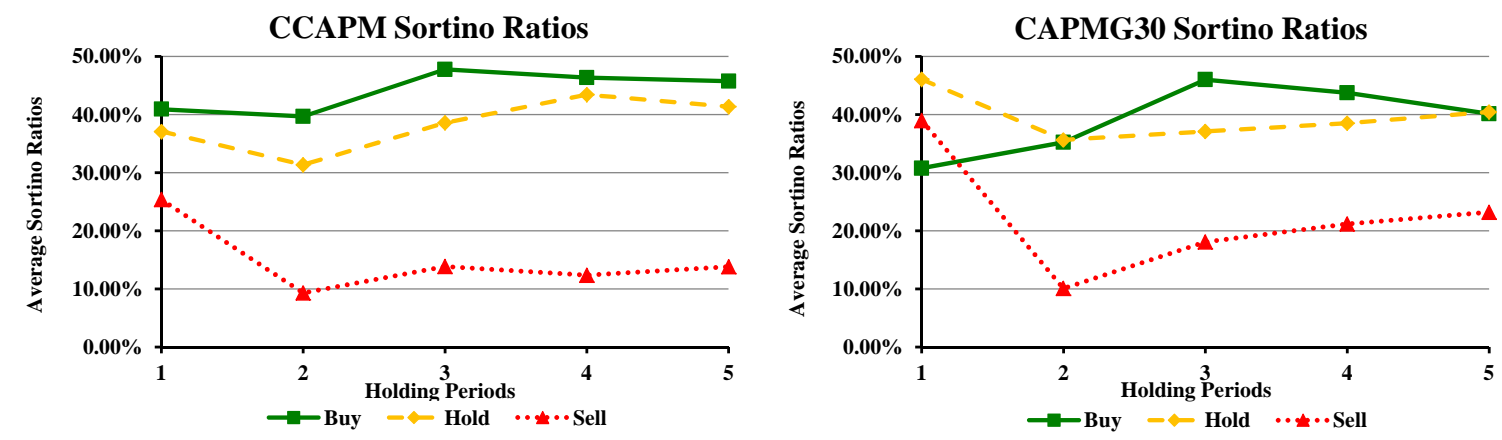

Figure 10: One- to five-year average annualized Sortino ratios on the buy, hold, and sell portfolios based on the CCAPM and CAPMG30 valuation models, respectively.

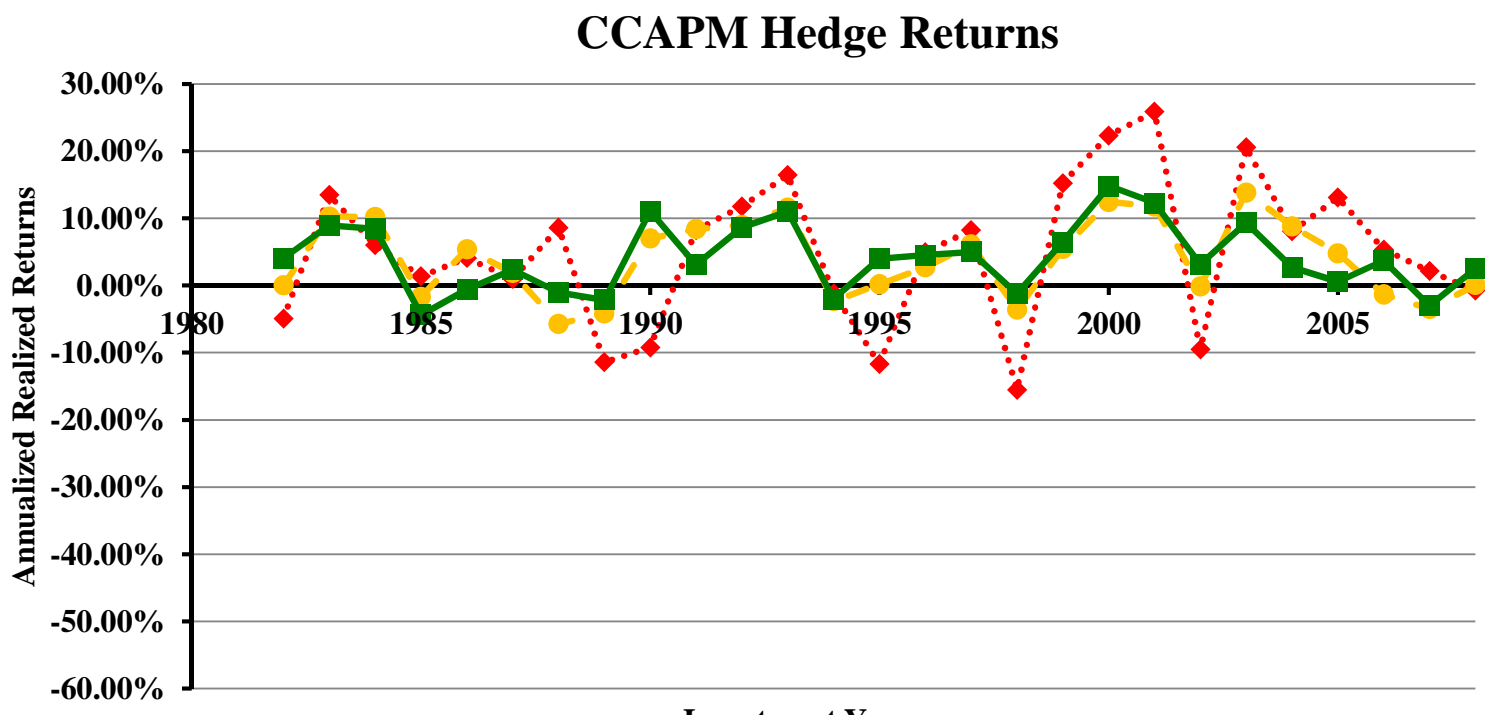

Investment Year

... One-year holding period (Avg. 4.92\%) - - Three-year holding period (Avg. 4.14\%)

$\longrightarrow$ Five-year holding period (Avg. 4.68\%)

Figure 11: Annualized realized returns on hedge portfolios (of going long in the buy portfolio and short in the sell portfolio) initiated at each valuation date (investment date) for one, three, and five-year holding periods. The buy and sell portfolios are based on the CCAPM valuation model. 


\section{CAPMG30 Hedge Returns}

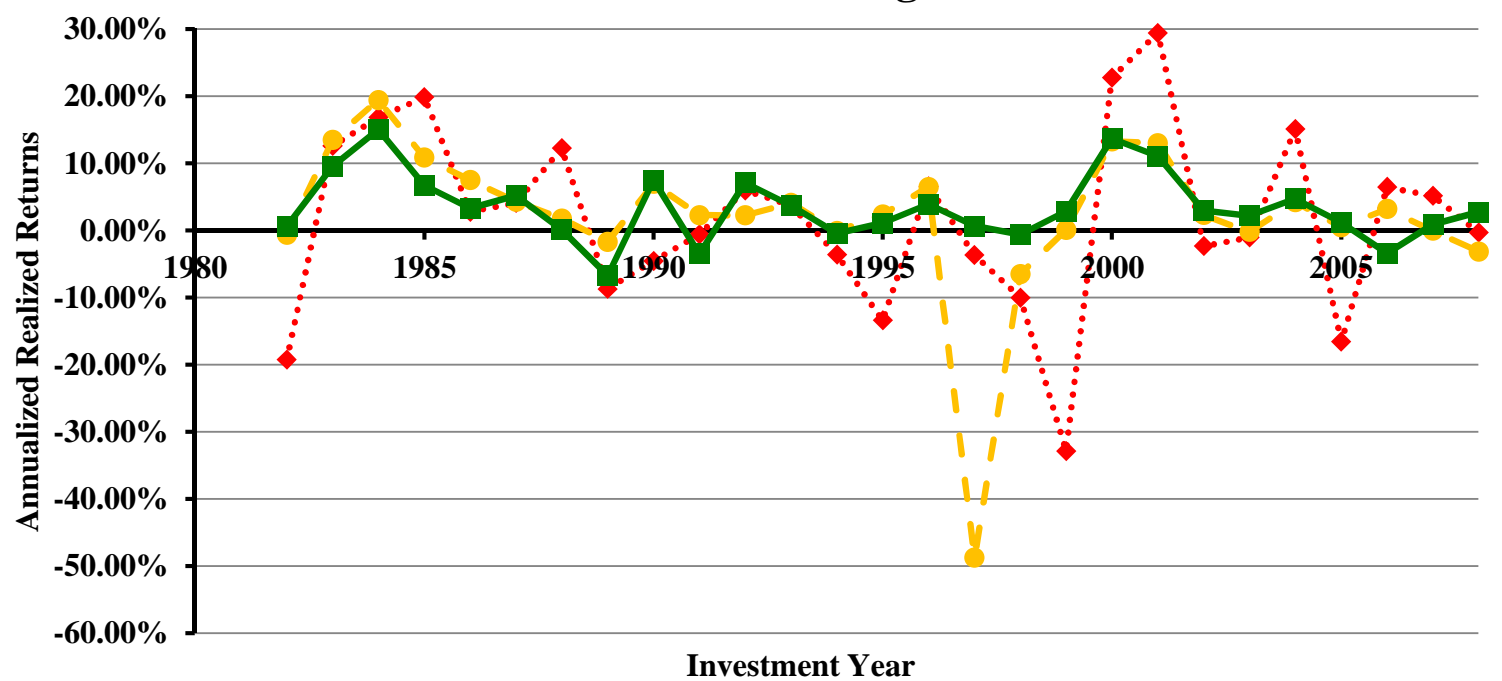

..... One-year holding period (Avg. 1.72\%)

- Three-year holding period (Avg. 2.20\%)

- Five-year holding period (Avg. 3.83\%)

Figure 12: Annualized realized returns on hedge portfolios (of going long in the buy portfolio and short in the sell portfolio) initiated each valuation date (investment date) for one, three, and five-year holding periods. The buy and sell portfolios are based on the CAPMG30 valuation model.
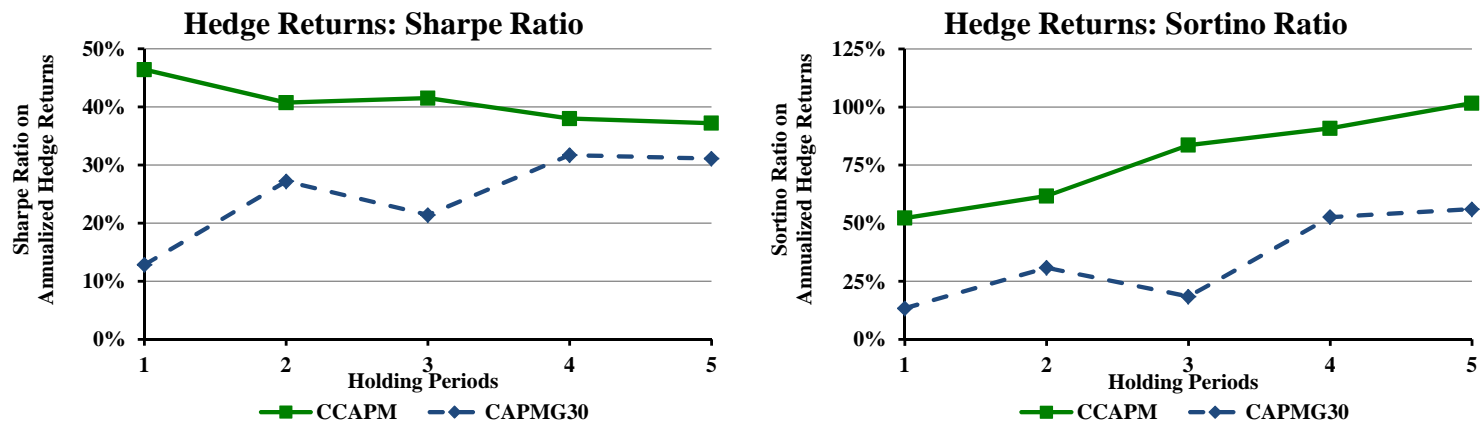

Figure 13: Sharpe and Sortino ratios on the time-series of annualized realized returns on buy-and-hold hedge portfolios based on the CCAPM and CAPMG30 valuation models, respectively. 


\section{Online appendix for}

\section{Consumption-based equity valuation}

In this online appendix, we perform robustness checks of our results in the published article "Consumption-based Equity Valuation." First, we include financial companies and utilities in the sample and, second, we perform an analysis in which we exclude the unreasonably high analysts' long-term growth forecasts from the forecasts of future residual income in the implementation of the valuation models. In both cases, we find in untabulated results that the single-factor CAPM clearly outperforms the three-factor Fama-French model in terms of median absolute valuation errors (MAVE), and that the CAPMG30 again is the best performing implementation of the single-factor CAPM in terms of both MAVE and the other performance measures used for valuation accuracy in Section 5 of the published article. Hence, we only report results for the CAPMG30 and the CCAPM valuation models in which we calibrate the growth rates at each valuation date.

\section{Including financial and utility companies}

In the analysis in the published article, we exclude financial and utility companies from the sample. This is the common approach in the empirical valuation literature, mainly because these firms have different business models, such as financial activities being part of the value creating activities in financial firms. However, as we are not separating financial and operating activities in our empirical study, but only forecast on a net income basis, it is possible to include these firms in our analysis. Including financial and utility companies increases the sample to 14,689 valuations of 2,479 companies.

Table 1 reports the valuation accuracy measures for the full sample of companies, including financial and utility companies, with yearly calibrations of growth rates for both the CCAPM and CAPMG30 valuation models. If these measures are compared to the measures without the financial and utility companies in the last two rows of Table 5 in the published article, the valuation accuracy results have, in fact, improved a little for both valuation models by including the financial and utility companies (or at least they have not deteriorated).

The noticeable differences are in the calibrated growth rates for the continuing values. The median growth rates have decreased from $5 \%$ to $2.8 \%$ for the CAPMG30 valuation model, and from $-10 \%$ to $-25 \%$ for the CCAPM valuation model. Hence, if the models are cal- 
ibrated to match the level of all stock prices at each valuation date, the continuing values must be reduced in the valuations. This is consistent with financial companies using markto-market accounting for larger fractions of their balance sheets than other companies and therefore they have less unrecorded goodwill in their continuing values. Similarly, utility companies have a highly regulated business model preventing them from generating large abnormal accounting profits and thus a high continuing value of future value creation. More generally, this suggests that using the same growth rate in continuing values for all industries is somewhat problematic. However, in the extreme, we could calibrate a growth rate for each firm at each valuation date and get a perfect match between model value and market price. Hence, only significant differences in the economics of the business models and the accounting principles (such as recognition of R\&D and use of mark-to-market accounting) should motivate using industry-specific growth rates.

\section{Insert Table 1 about here}

Figures 1 and 2 show the performance (in terms of excess returns and Sortino ratios) of the valuation models for forming portfolio strategies when financial and utility companies are included. These performance measures show that both models work well in identifying cheap and expensive stocks and, again, the CCAPM valuation model seems to have a better performance than the CAPMG30 valuation model. The Voung-test for model selection (as in Section 5.2.5 of the published article) has a $Z$-statistic of -2.8853 with a $p$-value of 0.0020 . That is, with the larger sample of firms, the CCAPM valuation model still produces pricing errors, which are better in predicting subsequent realized excess returns on individual stocks than the pricing errors generated from the CAPMG30 valuation model.

Insert Figures 1 and 2 about here

\section{Excluding long-term growth rates in forecasts of residual income}

In Table 2 of the published article, we report a median analysts' long-term growth rate (LTG) for three to five years ahead of $14 \%$ over our sample period from 1982 to 2008. Of course, such growth rates are not sustainable for extended periods and not consistent with realized growth rates. Hence, these forecasts seem to be overly optimistic, consistent with 
the evidence reported in the literature. In our analysis in the published article, we include the LTG forecasts in our forecasts of future residual income but in this online appendix, we investigate the consequences of omitting the LTG forecasts from our forecasting of future residual income for valuations. In particular, we apply a zero growth rate from three to five years ahead, and we calibrate growth rates from five years ahead in the CAPMG30 valuation model $(g)$ and from 12 years ahead in the CCAPM valuation model $(\mu)$, as in our analysis in the published article.

Table 2 reports the valuation accuracy measures with the revised forecast assumptions. If these measures are compared to the measures in the last two rows of Table 5 in the published article for which we include the LTG forecasts in the valuations, then the valuation accuracy of the models have deteriorated, especially for the CAPMG30 valuation model, and less so for the CCAPM valuation model. The calibrated median growth rate from year five in the CAPMG30 valuation model has increased from $5 \%$ to $7.6 \%$, while the calibrated median growth rate from year 12 in the CCAPM valuation model has increased from $-10 \%$ to $1 \%$. It is not surprising that the calibrated growth rates for matching the level of stock prices have increased. However, a growth rate of nearly $8 \%$ in the CAPMG30 valuation model seems to be an overly optimistic growth rate for value creation from five years ahead into infinity. This suggests that the estimated risk-premium in the risk-adjusted cost of equity in the order of $6 \%$ to $7 \%$ (see Table 2 in the published article) risk adjusts far too much such that a growth rate in the continuing value of $8 \%$ is required for the valuation model to match the level of stock prices.

Although the analysts' long-term growth rates seem overly optimistic, the deterioration of the valuation accuracy in both valuation models by omitting this information from the forecasts of future residual income suggest that these forecasted growth rates still contain useful information for matching the cross-section of stock prices.

\section{Insert Table 2 about here}

Figures 3 and 4 show the performance (in terms of excess returns and Sortino ratios) of the valuation models for forming portfolio strategies when we omit analysts' long-term growth rates from our forecasts of future residual income. These performance measures show that both models still work quite well in identifying cheap and expensive stocks even though their 
valuation accuracy has gone down. The Voung-test for model selection (as in Section 5.2.5 of the published article) has a $Z$-statistic of -1.8511 with a $p$-value of 0.0321 . Hence, although less significantly, the CCAPM valuation model still produces pricing errors, which are better in predicting subsequent realized excess returns on individual stocks than the pricing errors generated from the CAPMG30 valuation model.

Insert Figures 3 and 4 about here 
Table 1: Performance measure results including financial and utility companies for the standard valuation model using the one-factor CAPM-based risk-adjusted cost of equity compared to the CCAPM valuation model using yearly calibrated growth rates.

\begin{tabular}{|c|c|c|c|c|c|c|c|c|c|}
\hline \multirow{4}{*}{$\begin{array}{l}\text { Cal. each year } \\
\text { CAPMG30 } \\
\text { CCAPM }\end{array}$} & \multirow{2}{*}{ Growth rate } & \multicolumn{3}{|c|}{ VE } & \multicolumn{5}{|c|}{ AVE } \\
\hline & & Mean & Median & S.D. & Mean & Median & S.D. & $15 \% A V E$ & $25 \% A V E$ \\
\hline & $g=0.028$ & 0.255 & -0.009 & 0.998 & 0.588 & 0.341 & 0.856 & 0.777 & 0.630 \\
\hline & $\mu=-0.250$ & 0.050 & -0.015 & 0.401 & 0.313 & 0.231 & 0.287 & 0.651 & 0.467 \\
\hline
\end{tabular}

Note: Including financial and utility companies in the sample, the table presents the mean, median, and standard deviation of the percentage valuation errors $(P-V) / P$ and of the absolute percentage valuation errors $|P-V| / P$. $15 \% A V E(25 \% A V E)$ shows the percentage of companies for which the valuation error is larger than $15 \%$ (25\%). All valuations for the standard model (CAPM) are based on the one-factor CAPM cost of equity with the market risk premium estimated over 30 years prior to the valuations and a growth rate in residual income equal to $g$ from year 5 . All valuations for the CCAPM model using the term structure of interest rates assume a growth rate of risk-adjusted expected residual income returns equal to $\mu$ from year 12. The growth rates $g$ and $\mu$ are calibrated within each year's valuations so as to minimize the squared median VE for that year. The reported growth rates are median implied growth rates for the 27 years of valuations.

Table 2: Performance measure results excluding analysts' LTG forecasts for the standard valuation model using the one-factor CAPM-based risk-adjusted cost of equity compared to the CCAPM valuation model using yearly calibrated growth rates.

\begin{tabular}{|c|c|c|c|c|c|c|c|c|c|}
\hline & Growth rate & \multicolumn{3}{|c|}{ VE } & \multicolumn{5}{|c|}{ AVE } \\
\hline Cal. each year & & Mean & Median & S.D. & Mean & Median & S.D. & $15 \% A V E$ & $25 \% A V E$ \\
\hline CAPMG30 & $g=0.076$ & 0.641 & -0.057 & 2.155 & 1.100 & 0.502 & 1.966 & 0.849 & 0.748 \\
\hline CCAPM & $\mu=0.010$ & 0.139 & 0.029 & 0.591 & 0.443 & 0.300 & 0.438 & 0.723 & 0.567 \\
\hline
\end{tabular}

Note: Excluding analysts' consensus long-term growth rates from forecasts of residual income, the table presents the mean, median, and standard deviation of the percentage valuation errors $(P-V) / P$ and of the absolute percentage valuation errors $|P-V| / P .15 \% A V E(25 \% A V E)$ shows the percentage of companies for which the valuation error is larger than $15 \%$ (25\%). All valuations for the standard model (CAPM) are based on the one-factor CAPM cost of equity with the market risk premium estimated over 30 years prior to the valuations and a growth rate in residual income equal to $g$ from year 5 . All valuations for the CCAPM model using the term structure of interest rates assume a growth rate of risk-adjusted expected residual income returns equal to $\mu$ from year 12 . The growth rates $g$ and $\mu$ are calibrated within each year's valuations so as to minimize the squared median VE for that year. The reported growth rates are median implied growth rates for the 27 years of valuations. 

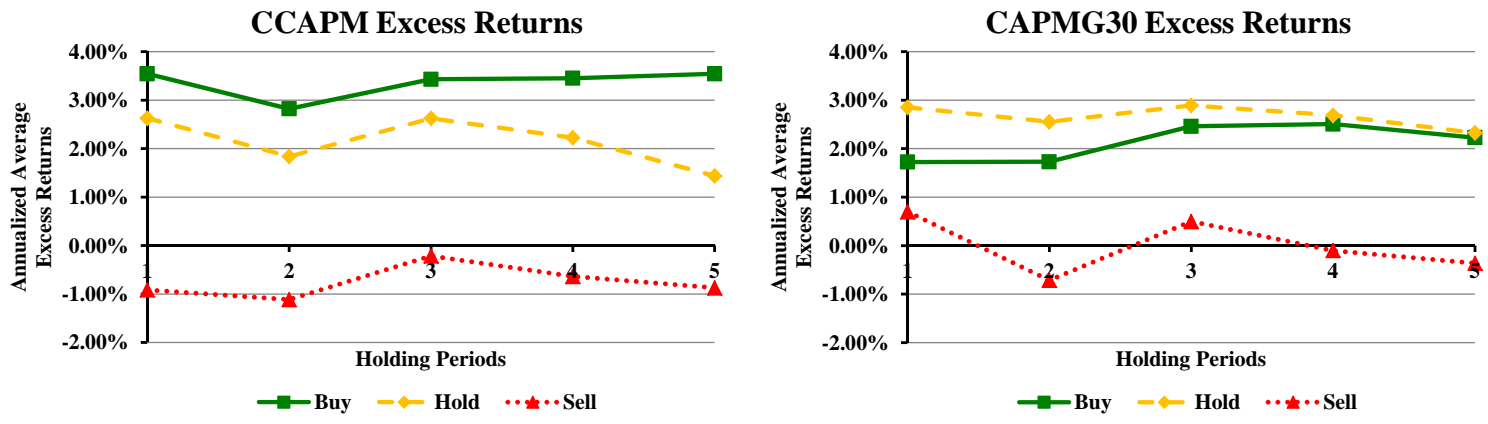

Figure 1: One- to five-year annualized average excess returns on the buy, hold, and sell portfolios based on the CCAPM and CAPMG30 valuation models, respectively, when financial and utility companies are included in the sample.
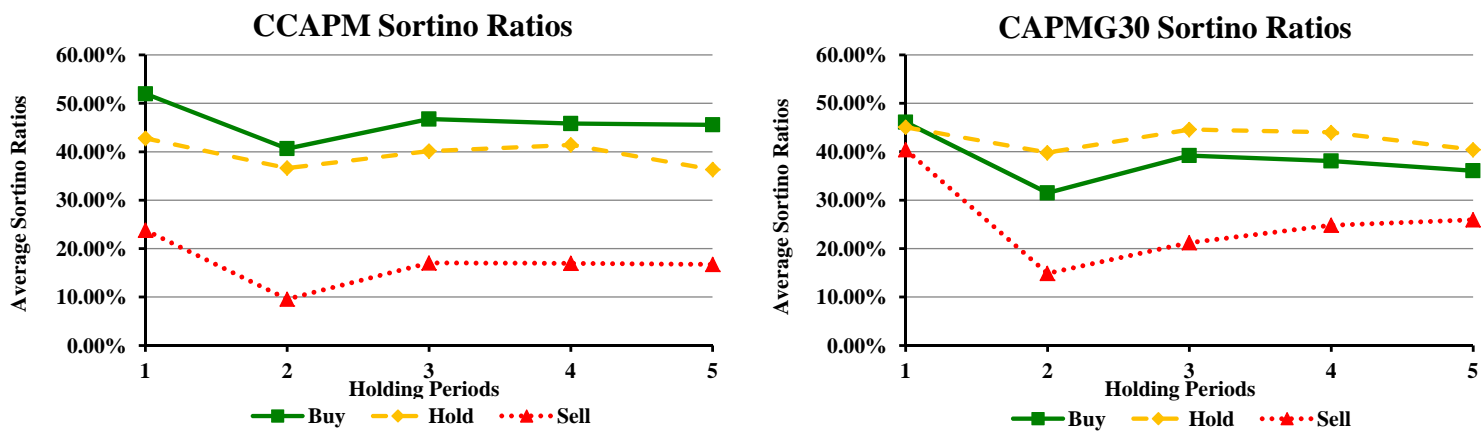

Figure 2: One- to five-year average annualized Sortino ratios on the buy, hold, and sell portfolios based on the CCAPM and CAPMG30 valuation models, respectively, when financial and utility companies are included in the sample. 

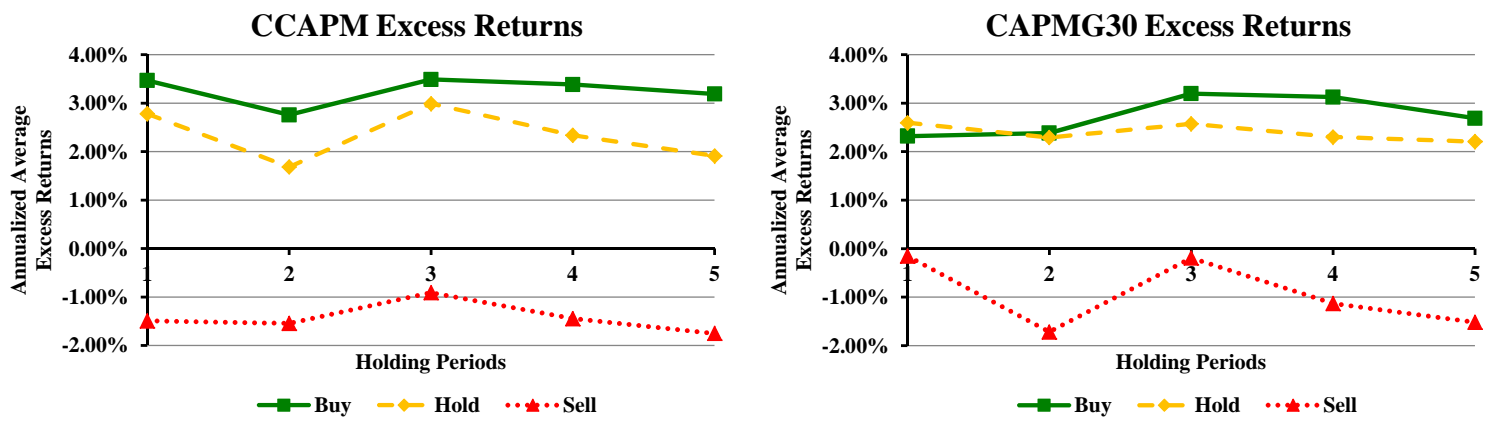

Figure 3: One- to five-year annualized average excess returns on the buy, hold, and sell portfolios based on the CCAPM and CAPMG30 valuation models, respectively, when analysts' forecasts of long-term growth rates are omitted in forecasting residual income.
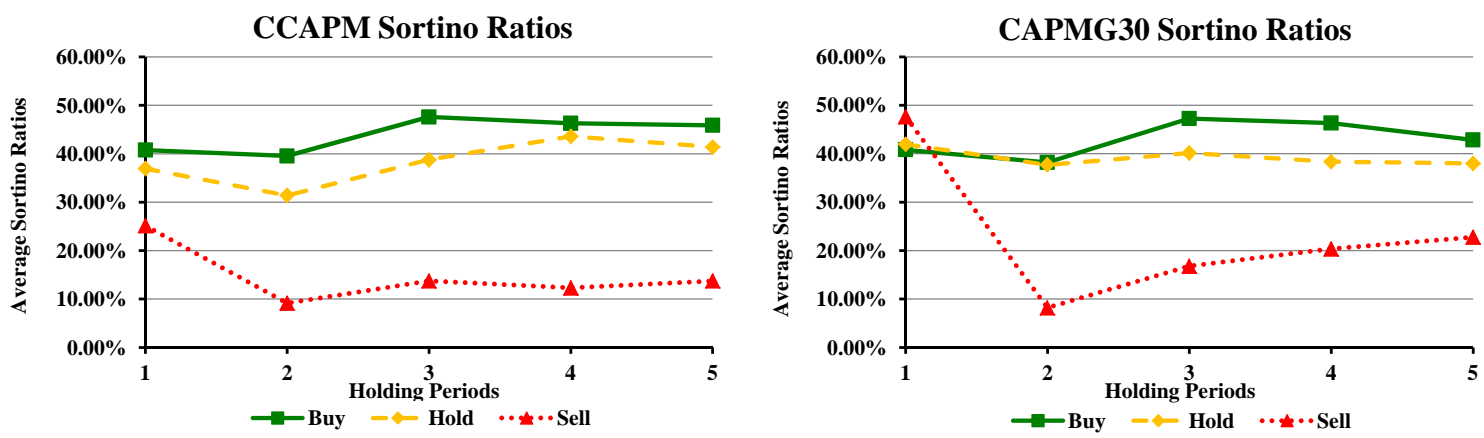

Figure 4: One- to five-year average annualized Sortino ratios on the buy, hold, and sell portfolios based on the CCAPM and CAPMG30 valuation models, respectively, when analysts' forecasts of long-term growth rates are omitted in forecasting residual income. 